VOLUME 34, ARTICLE 39, PAGES 1075-1128

PUBLISHED 23 JUNE 2016

http://www.demographic-research.org/Volumes/Vol34/39/

DOI: 10.4054/DemRes.2017.34.39

Research Article

\title{
Child mortality estimation: An assessment of summary birth history methods using microsimulation
}

\section{Andrea Verhulst}

(c) 2017 Andrea Verhulst.

This open-access work is published under the terms of the Creative Commons Attribution NonCommercial License 2.0 Germany, which permits use, reproduction \& distribution in any medium for non-commercial purposes, provided the original author(s) and source are given credit. See http://creativecommons.org/licenses/by-nc/2.0/de/ 


\section{Table of Contents}

$1 \quad$ Introduction 1076

$2 \quad$ Summary birth history methods under study 1077

$\begin{array}{lll}2.1 & \text { The Brass method and variants } & 1077\end{array}$

2.2 The methods of the Institute for Health Metrics and Evaluation 1079

3 Research questions $\quad 1080$

$4 \quad$ Methods 1083

4.1 Data 1083

4.2 Microsimulation with Socsim 1083

$\begin{array}{ll}4.3 & \text { Construction of the assessment tool } \\ & 1085\end{array}$

$5 \quad$ Results 1087

$\begin{array}{lll}5.1 & \text { Maternal age variants } & 1087\end{array}$

$\begin{array}{lll}5.2 & \text { Time since first birth variants } & 1094\end{array}$

6 Discussion 1096

$\begin{array}{lll}7 & \text { Acknowledgements } & 1098\end{array}$

$\begin{array}{ll}\text { References } & 1099\end{array}$

$\begin{array}{ll}\text { Appendices } & 1103\end{array}$ 


\title{
Child mortality estimation: An assessment of summary birth history methods using microsimulation
}

\author{
Andrea Verhulst ${ }^{1}$
}

\begin{abstract}
BACKGROUND

Two types of indirect methods for estimating child mortality rates from summary birth histories (number of children ever born and children dead) are currently available to users: model-based methods derived from the pioneering work of Brass and empirically based methods developed more recently at the Institute for Health Metrics and Evaluation (IHME).
\end{abstract}

\section{OBJECTIVE}

The objective of this study is to evaluate the performance of six alternative indirect methods based on summary birth histories.

\section{METHODS}

Using microsimulation based on the 1950-2010 fertility and mortality rates of the United Nations' World Population Prospects, estimates generated by six alternative indirect methods were compared against benchmark direct estimates for 82 countries.

\section{RESULTS}

The results show that the IHME methods outperform the classical Brass method. In particular, the cohort-derived method is able to produce robust past child mortality trends across a variety of demographic regimes. However, no method produces robust recent estimates prior to data collection. When data are classified by time since first birth, methods perform better than with maternal age classification.

\section{CONCLUSIONS}

This study suggests that the maternal age variant of the IHME cohort-derived method is the best option for estimating child mortality from past censuses. For future censuses, it would be worthwhile adding an extra question on date of first birth.

\section{CONTRIBUTION}

This study provides new recommendations on which method to use depending on the data available, as well as for future population census collection.

\footnotetext{
${ }^{1}$ Université catholique de Louvain, Belgium. E-Mail: andrea.verhulst@uclouvain.be.
} 


\section{Introduction}

Monitoring progress on child survival has been recognized to be of prime importance for public health and policy making. Most prominently, the United Nations Millenium Development Goal 4 set a target of reducing the under-five mortality rate ${ }^{2}$ (U5MR) by two thirds between 1990 and 2015. In the post-2015 development agenda, Sustainable Development Goals target inequalities within countries, and challenge the existing methods of measuring child mortality at the subnational level and for population subgroups (UNICEF 2015).

Against this backdrop, summary birth histories (SBHs), widely collected in censuses and surveys in developing countries, constitute a key source of information for such monitoring purpose. This study focuses on the indirect methods for estimating U5MRs from SBH data. Using microsimulation, we compare estimates generated by six alternative indirect methods against benchmark direct estimates. The objective is to evaluate comparatively the performance of the methods and provide guidance on which one to use depending on the data available.

The most reliable data source for tracking progress on the U5MR is the vital registration system. This poses challenges in most developing countries where this system does not exist or is incomplete. Under these conditions, analysts mostly rely on two classes of alternative data: SBHs and full birth histories (FBHs) (Hill 2013c). SBHs are collected by asking about women's number of children ever born (CEB) and children dead (CD). FBHs include additionally the timing of births and deaths. In this case, child exposure to mortality risk is directly calculated by measuring the duration between births and the time of survey or using the age at death. Instead, SBHs require an indirect method to approximate the exposure. The classical Brass method uses the age of the mother as a proxy to do so (Brass and Coale 1968).

Both approaches are potentially affected by systematic errors. Direct estimates of the U5MR derived from FBHs are prone to data errors, mainly omissions and displacements over time of births and deaths (Hill 2013a). Indirect estimates derived from SBHs with the Brass method are additionally vulnerable to violations of underlying assumptions about past fertility and mortality (Hill 2013b). In particular, they are known to be strongly biased for the period closer to the time of data collection.

The direct estimation method based on FBHs is usually considered best practice when no comprehensive vital registration is available. However, the costs of acquiring quality information (training of interviewers, fieldwork supervision, etc.) make this approach time-consuming and expensive. Consequently, the FBH approach is regarded as ill-suited to apply to very large-scale data collection such as population censuses. FBHs are thus only collected in sample surveys such as the Demographic and Health Surveys

\footnotetext{
${ }^{2}$ The under-five mortality rate, also commonly denoted ${ }_{5} q_{0}$, is the probability of dying between birth and the age of 5 .
} 
(DHS). In contrast, the SBH approach has the advantage of being low-cost due to the minimal amount of information needed. As a result, SBHs are habitually collected in censuses (UN 2013a), and as such are better able to support growing requests for subnational and local estimates.

The plan of the paper is as follows: section 2 presents the SBH methods under study and summarizes their mechanics, as well as underlying assumptions. Section 3 explicates the adressed research questions. Section 4 describes the data used and the construction of the assessment tool based on microsimulation. Section 5 displays and analyzes the results. Finally, section 6 summarizes the main results and discusses the limitations of the study.

\section{Summary birth history methods under study}

Two types of indirect methods for analyzing SBHs are currently available to users: modelbased methods derived from Brass's pioneering work (Brass and Coale 1968), and empirically based methods developed more recently at the Institute for Health Metrics and Evaluation (IHME) by Rajaratnam et al. (2010).

\subsection{The Brass method and variants}

In the absence of information about the timing of births and deaths, the Brass indirect method makes use of maternal age as a proxy for approximating the children's mean length of exposure to the risk of dying. In essence, the method uses multipliers to transform proportions dead of children, derived from SBHs and classified by five-year age group (15-19, etc., 45-49), into cohort-specific probabilities of dying $\left({ }_{1} q_{0},{ }_{2} q_{0},{ }_{3} q_{0},{ }_{5} q_{0}\right.$, ${ }_{10} q_{0},{ }_{15} q_{0}$, and ${ }_{20} q_{0}$ ). The original multipliers were calculated using relations between the proportions dead of children and probabilities of dying captured in stable populations. These stable populations were simulated analytically using model age patterns of fertility and mortality. The method has been improved over time supported by a number of variants of the original formulation. The standard version of the method (UN 1983) was proposed by Trussell (1975) who calculated multipliers using a regression approach first developed by Sullivan (1972). In the Trussell version we test in this paper, the user selects an appropriate model life table among the Coale and Demeny families (Coale, Demeny, and Vaughan 1966), according to the comparison of ${ }_{1} q_{0}$ and ${ }_{4} q_{1}$ from an external source (e.g. a FBH survey). To identify the underlying fertility pattern, the user must compute parity ratios $\left(P_{15-19} / P_{20-24}\right.$ and $\left.P_{20-24} / P_{25-29}\right)$, which aim to capture approximately the time distribution of past births.

The Trussell version also includes a procedure proposed by Feeney (1980) that al- 
locates estimates over time. This makes it possible to estimate a trend in child mortality for a period of about 15 years prior to data collection ${ }^{3}$. Since age of mother is used as proxy for the children's exposure to mortality, the estimates that are closer to the time of data collection are associated with the declarations of the younger women. Conversely, estimates situated further back in time are derived from the cohorts born to older women.

The main assumption of the Brass method is that the population has been approximately stable. First, if fertility has been changing, the parity ratios computed at the time of data collection are distorted for true cohorts. This generates biases for estimates situated further back in time. Second, if mortality has been changing, the estimates for past cohorts will not reflect mortality for a period of time close to data collection. However, as shown empirically by Feeney (1980), the assumption of constant mortality can be relaxed to allow linear monotonic change when using the timing procedure (but the method remains incapable to capture abrupt changes in mortality).

Third, another important assumption of the method is that mortality does not vary by age of mother. Violation of this assumption usually leads to severe upward biases for recent estimates associated with women aged 15-19 and 20-24 (situated respectively around one and two years prior to data collection). This is due to above average risks of dying associated with young women. As a consequence, those recent estimates are usually ignored. The most robust estimate from the Brass method is considered the one associated with women aged 30-34, corresponding to mortality in the neighborhood of six years prior to data collection (Hill et al. 2012).

To improve recent estimates, a variant of the Brass method, based on the time elapsed since first birth instead of the age of mother, was developed by Hill and Figueroa (2001). This alternative classification of proportions dead considers jointly children born to women of different ages in the five-year duration groups (0-4, etc., 20-24) in order to reduce the biases associated with young women. Additionally, Hill (2013b) suggested that the variant would also better address changing fertility. This is because parity ratios $\left(P_{0-4} / P_{5-9}\right.$ and $\left.P_{5-9} / P_{15-19}\right)$ used to capture the time distribution of past births would be less vulnerable to distortion over time. However, performance of this variant has never been extensively evaluated.

The major drawback of the time since first birth variant is that it requires data on month and year of first birth. This item was not collected in past censuses, though available in DHS surveys as well as in the UNICEF's Multiple Indicator Cluster Surveys (MICS).

\footnotetext{
${ }^{3}$ After probabilities of dying at different ages of childhood are transformed into U5MRs using the relational logit system of model life tables (UN 1983).
} 


\subsection{The methods of the Institute for Health Metrics and Evaluation}

The IHME methods were developed more recently (Rajaratnam et al. 2010) in order to overcome the standard assumptions of the Brass method. Based on cohort and period measures of $\mathrm{CD} / \mathrm{CEB}$, the methods use random effects models to capture the country and regional variations in fertility and mortality in real datasets (166 DHS surveys collected from 1986 to 2008).

First, a cohort-derived method uses the same cohort data and involves similar procedures as those used by the Brass method. The method is based on the relation between proportions dead of children and U5MRs observed in surveys, controlling for the level and age pattern of fertility with the same parities than in the Brass method. The average timing of deaths for a given five-year cohort was first modeled through regression. Then, the corresponding period-specific U5MR derived from FBHs was regressed against the proportion dead of the cohort producing coefficients for prediction. The method aims to relax the original stable population assumption, and does not require choosing a model life table. Excess mortality related to young women was expected to be captured in the DHS data. However, due to errors associated with the small size of the subsamples of mothers aged 15-19 in surveys, the method produces unstable results (Rajaratnam et al. 2010). As a consequence, and as happens in the case of the Brass method, the estimate based on this age group is ignored. Therefore, the most recent estimate of mortality is associated with age group 20-24 and corresponds approximately to 3 years prior to data collection.

Second, a period-derived method transforms period proportions dead of children into U5MRs for each year prior to the data collection up to 25 years, thus producing very recent estimates. The period proportions dead of children are obtained using expected frequency distributions of births and deaths over time. These time distributions were computed from DHS datasets for mothers classified by two-year age group, number of $\mathrm{CD} / \mathrm{CEB}$ and world region. Again, the corresponding period-specific U5MRs derived from FBHs were regressed against the annual period proportions dead. The underlying assumption is that the time distributions can be generalized across space and time. Computation of period proportions dead requires access to microdata due to the non-standard tabulation of mothers.

Both the cohort- and period-derived methods feature random effects for countries that have at least one DHS survey included in the modeling. These are additive constants that adjust the predicted values associated with each country. Both methods have also a maternal age and a time since first birth variant to capture children's exposure to mortality, thus totaling four variant methods. A fifth method combines these four using a loess smoothing regression, and is considered to be the one with optimal performance.

Although the IHME methods are intended to relax the standard assumptions of the Brass method, they are not expected to be uniformly better. First, as the Brass method, 
IHME methods cannot detect sudden changes in mortality. Second, and also as the Brass method, IHME methods are potentially vulnerable to selection biases due to the association between child mortality and mother survival ${ }^{4}$.

In this paper, the performance of six alternative SBH methods are evaluated: the Brass method and the IHME cohort- and period-derived methods, in each case for both the maternal age and time since first birth variants. Different combinations of IHME methods are also examined. Table 1 summarizes the charateristics of the six methods (abbreviation in the text, required data, mathematical expressions, and assumptions).

Figure 1 shows the U5MR indirect estimates of each of these methods when applied to the 2010 Colombian DHS survey, and compared against direct estimates derived from the FBHs collected in the same survey. The four IHME methods, as well as the time since first birth variant of the Brass method, tend to produce estimates that are more consistent with the direct ones than the standard maternal age variant of the Brass method, both for recent and past periods. Using the FBH estimates as reference, Rajaratnam et al. (2010) concluded that their combined method outperforms the standard Brass method by an average of $43.7 \%$. However, this validation exercice is somewhat limited by weak independence across the DHS datasets used to both build and validate the IHME methods ${ }^{5}$.

\section{Research questions}

In this study, we carry out a systematic assessment of the Brass and IHME methods through a broad set of fertility and mortality regimes generated by microsimulation. We address the following questions: (1) How robust are the estimates generated by the IHME methods compared to those produced by the Brass method? (2) How do the six alternative SBH methods perform under different fertility and mortality regimes? (3) Which SBH methods should be preferred depending on the available data? (4) Should the additional data about date of first birth be collected more widely in future censuses (and household surveys) in order to apply the corresponding variant methods?

\footnotetext{
${ }^{4}$ This kind of association generates selection biases when data are collected retrospectively. Children that are not captured due to mother's death (or absence) are generally considered at higher risk of dying (Hill 2013c).

5 The validation data are the same as the data used to build the models. As a consequence, the results of the validation exercice are invitably contaminated. However, Rajaratnam et al. (2010) also realized an out-ofsample validation process whereby they randomly selected $80 \%$ of the DHS surveys from which they derived the models, and then used these models to predict for the remaining $20 \%$. Still, this out-of-sample validation remains exposed to potential systematic data errors in the DHS surveys.
} 
Table 1: Characteristics of the summary birth history methods under study

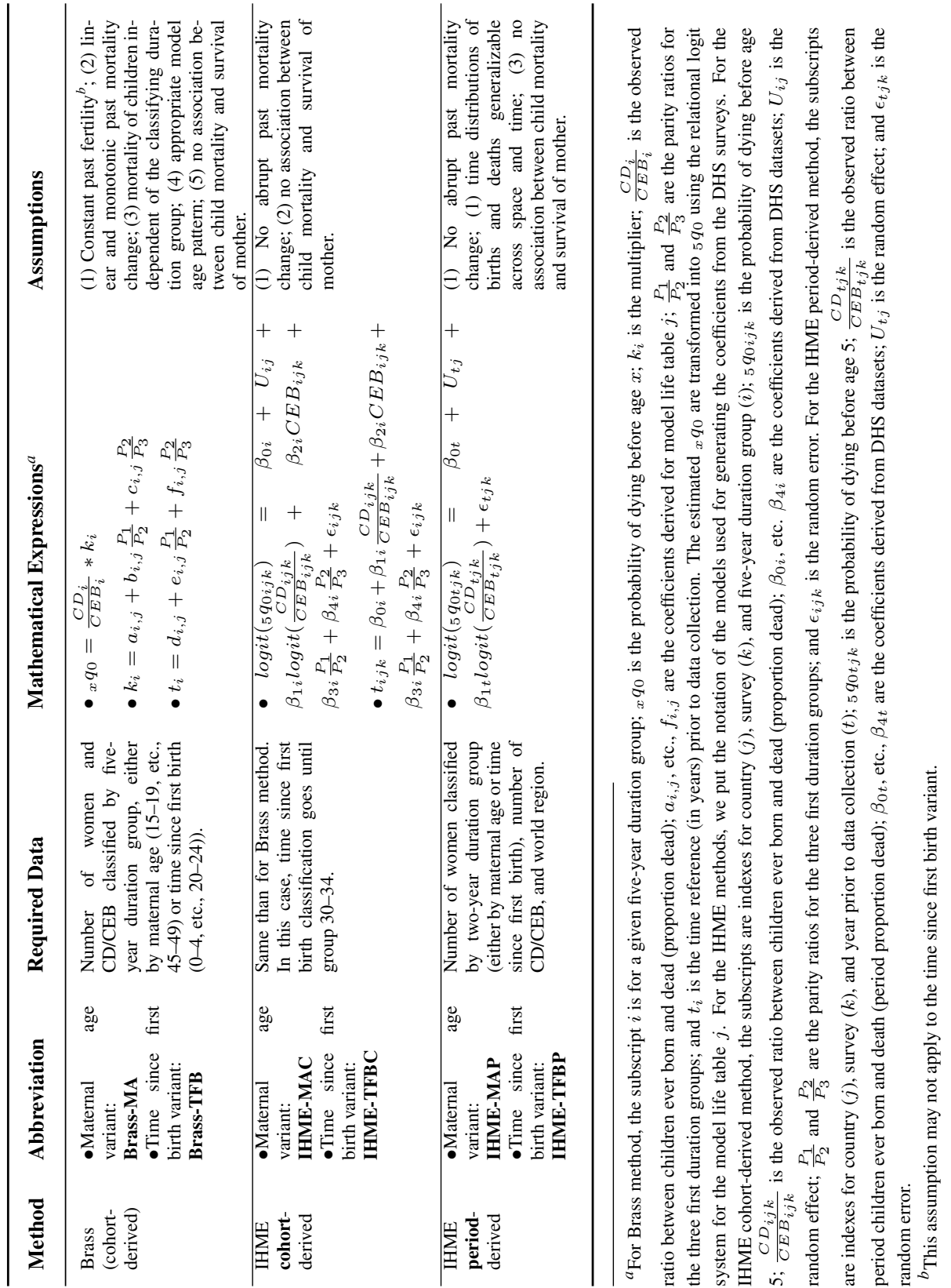


Figure 1: $\quad$ Comparison of summary birth history (SBH) and full birth history (FBH) estimates of the under-five mortality rate, derived from the 2010 Colombian DHS survey for six summary birth history methods
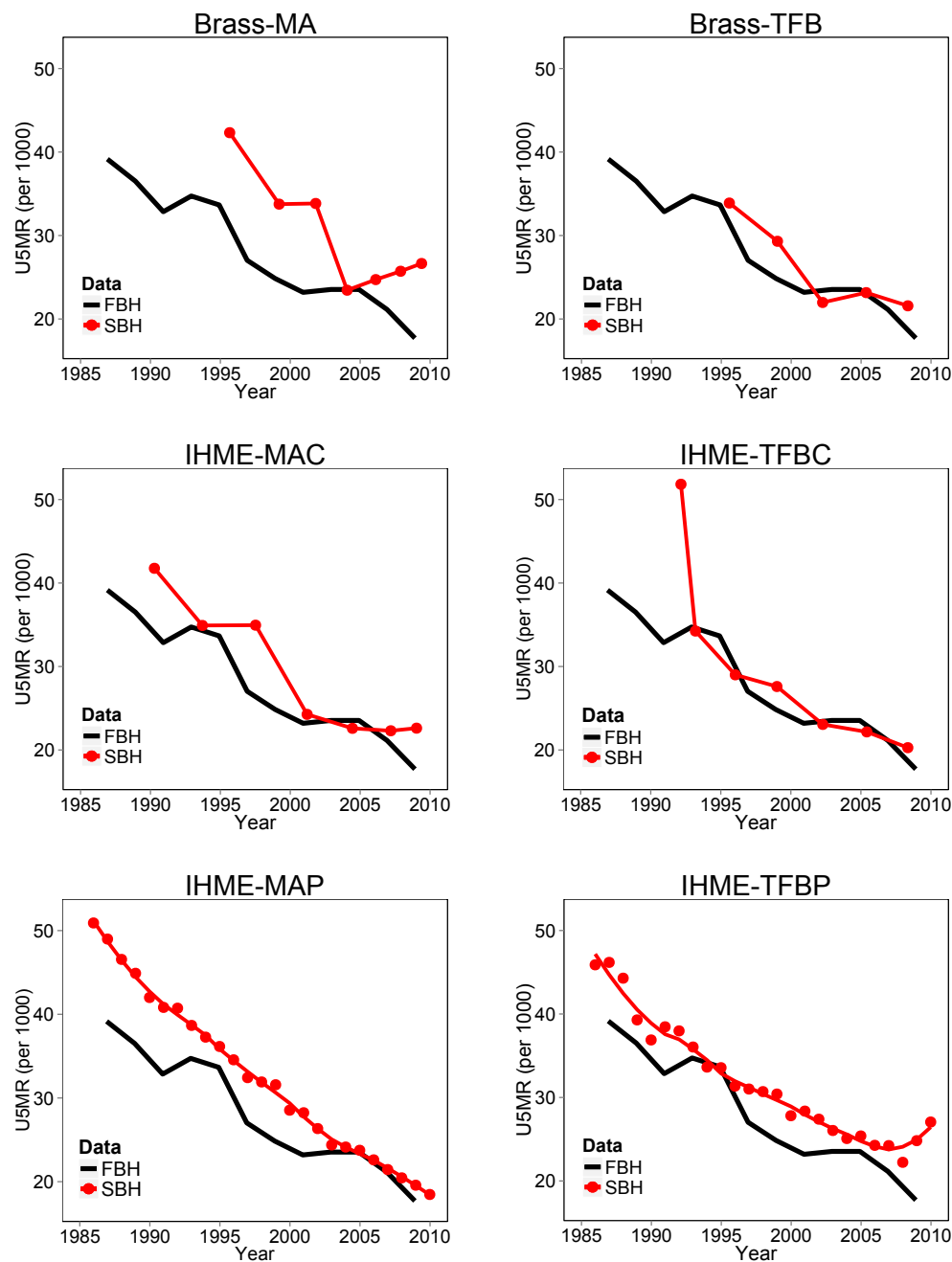

Note: Summary birth history methods are maternal age and time since first birth variants of the Brass method (Brass-MA and -TFB), IHME cohort-derived method (IHME-MAC and -TFBC), and IHME period-derived method (IHME-MAP and -TFBP). 


\section{Methods}

\subsection{Data}

The simulations were based on country-specific fertility and mortality rates retrieved from the 2012 Revision of the United Nations World Population Prospects (WPP) for the period 1950-2010. Countries were selected depending on the coverage of their vital registration system. Only countries with less than $90 \%$ coverage, according to the UN Statistics Division, were considered (UN 2014a). Simulations were also performed for countries for which indirect estimates are included in the database created by the United Nations Inter-agency Group for Child Mortality Estimation (UN IGME). However, we excluded countries with less than 500.000 inhabitants in 2010, as well as those from Oceania that falls outside the regional coverage of the IHME methods. Furthermore, we also excluded countries with explicit HIV/AIDS modeling in the WPP, and other countries stricken by crises, such as the North Korean (DPR) famine crisis from the 1990s. These exclusions rest on our knowledge that episodic and abrupt changes in mortality due to epidemics, natural disasters, or political and economic crises lead to poor performance of the SBH methods. Silva (2012) showed that the Brass method should be used only for populations that have experienced either smooth mortality declines or only short periods of excess in their recent past. Rajaratnam et al. (2010) and Zimmerman (2014) also pointed out that the IHME methods are poorly suited to short-term fluctuations in mortality.

In all, 82 country-specific simulations were computed. They correspond to relatively smooth fertility and mortality trends that are distinguished by their level and rate of decline. Countries were divided into four world regions according to the classification used by Rajaratnam et al. (2010): Asia (ASIA), Latin America and the Caribbean (LATC), Northern Africa and the Middle-East (NAME), and the combination of (i) Southern Eastern and (ii) Western and Central Sub-Saharan Africa, considered as a single Sub-Saharan region (SSA) due to the similarity of the results. A list of the selected countries and details about input rates are given in Appendix A.

DHS surveys were also used to capture and simulate the variation of the mortality risk by age of mother. More specifically, the 135 publicly available standard datasets collected between 1990 and 2013 in 46 of the 82 selected countries (see Appendix A) were used to produce a model of relative infant mortality risks by age group of the mother for each world region (see section 4.3).

\subsection{Microsimulation with Socsim}

Simulations were developed using Socsim, a dynamic stochastic program wherein the unit of observation is the individual (Mason 2013, 2014). Socsim is a free, open-source program available on the Demography Lab of the University of California, Berkeley. 
Written in the 1970's, it was designed to study the kinship networks shaped in different demographic regimes (Hammel et al. 1976).

There are several reasons that simulating populations at the individual level with Socsim is advantageous for assessing indirect methods. First, Socsim keeps track of a mother's identification number. Hence, the tabulations that are required (see table 1) to apply the SBH methods can be easily extracted from the simulation outputs ${ }^{6}$. Second, the U5MRs that underlie the simulations can be re-estimated directly using recorded dates of births and deaths in Socsim. These direct estimates constitute a benchmark against which we can assess the biases in the indirect estimates.

Within Socsim, the input and output populations are structured as data files in which individuals are single observations. In additional files, demographic rates (which include fertility, mortality and other transition rates) are specified as monthly probabilities of occurrence. When a simulation is run, individuals are exposed to monthly risks for the specified events according to their sex, age or other defined group affiliation. The output population file records all affiliations, event occurrence dates (in months), and key identification numbers for kinship linkage ${ }^{7}$. This allows reconstruction of all women's birth histories.

At any time during the simulation, individuals have an event scheduled. The selection of the event and a waiting time until it occurs are determined through an event lottery within a competing risk framework. The algorithm is conceptually equivalent to comparing a random number drawn from the uniform $(0,1)$ distribution interval to the probability of occurrence of the event by a particular month $T$.This probability is given by the following expression:

$$
1-\prod_{t=0}^{T}\left(1-p_{t}\right)
$$

where $p_{t}$ is the probability of the event's occurrence in month $t$ conditional on it not having occurred at any time before $t$. When the random number falls below the probability, the corresponding event is virtually scheduled. Then, the event with the shortest waiting time is assigned as the next one to the individual's calendar. This random procedure is repeated after each event occurrence.

Due to the inherent stochastic nature of Socsim, the events are modeled as ran-

\footnotetext{
${ }^{6}$ These tabulations are difficult to represent analytically or with standard macrosimulation software. Although proportions dead of children by age of mother or time since first birth can be represented formally (see Appendix B), the standard expressions typically rely on the assumption of stability. Also computation of period proportions dead of children for the corresponding IHME method requires a count of women by number of $\mathrm{CD} / \mathrm{CEB}$, quantities that can only be retrieved from microdata.

${ }^{7}$ Socsim is based on a closed population model, that is, no individual can enter the population by a means other than birth, or exit it by another means than death. That way, Socsim does not truncate any kinship relation and allows the entire genealogy of the population to be known with certainty (Mason 2014).
} 
dom variables (with piecewise exponential distributions). Therefore, unlike deterministic macrosimulation, the expected value of an event is always affected by a sampling error in the microsimulation outputs (Van Imhoff and Post 1998). However, the variance of any quantity of interest can be estimated by running a simulation multiple times.

\subsection{Construction of the assessment tool}

Each country-specific simulation starts out with the same stable population. This population was generated by maintaining constant a high regime of fertility (total fertility rate $=5$ ) and mortality (U5MR $=220$ per 1000) for 100 years $^{8}$. We then used the vital rates from the WPP as inputs in the computations for each year segment during the period 1950-2010. To minimize random error, each of these country-specific simulations was replicated, and quantities of interest extracted and summed, 100 times (a check on the precision of the simulations is developed in Appendix B). As a consequence, no significant sampling errors affect the simulated populations, and data extracted from them are equivalent to census information.

The populations were also generated without recall errors (e.g. omissions of births). Hence, sampling and non-sampling errors that potentially affect real data were removed. This allows us to focus on the instrinsic performance of SBH methods in different demographic regimes, or equivalently, focus on the consequence of departures from assumptions related to the prevailing demographic regimes. However, as an exception, we did not embed into the simulation selection biases caused by the association between child mortality and mother survival. The potential impact of the non-simulated biases and errors on estimates is discussed in section 6 .

In order to vary the risk of mortality as a function of the age of mother at birth, a death rate multiplier was introduced to rescale the baseline mortality hazard rate schedule according to the individual-level characteristics at birth ${ }^{9}$. To capture different patterns across world regions, a hazard regression model was applied to the DHS data (see Appendix A). The risks were estimated only for infants (age 0 to 1 ), considering that maternal age ceases to have any relevant impact on children over 1 year (Fernandez 1985). Figure 2 shows the four estimated regional models of infant mortality risks that were included in the simulations. They mainly differ in the excess mortality associated with the age group 15-19, ranging from 1.1 to 1.5 . Hence, the simulated maternal age effect was lower for Latin America and the Caribbean (LATC) and higher for Northern Africa and the Middle-East $(\mathrm{NAME})^{10}$.

\footnotetext{
${ }^{8}$ The initial population is a small set of 3,000 individuals with no particular age or sex distribution.

${ }^{9}$ For this purpose a special "verhulst" version of Socsim was programmed (revision 52:53M, February 6, 2015).

${ }^{10}$ According to Collumbien and Sloggett (2001), changes in excess mortality may occur when fertility declines. A decrease can be the result of postponment of first births to a later, less risky age (upper limit of the age group
} 


\section{Figure 2: $\quad$ Regional models of relative infant mortality risks by age of mother} at birth derived from DHS surveys

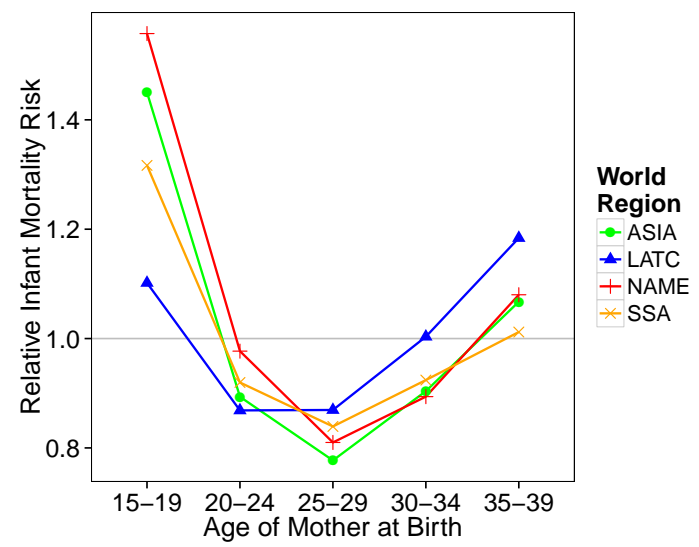

Note: Regions are Asia (ASIA), Latin America and the Caribbean (LATC), Northern Africa and the Middle-East (NAME), and Sub-Saharan Africa (SSA).

All required data for the application of SBH methods (see Table 1) were extracted from the simulation outputs using the mother's identification number. Data were extracted as if they had been collected at the end of 2010 . The indirect methods were then applied to the simulated data using the equations and coefficients provided by Hill (2013b) for the Brass method and by Rajaratnam et al. (2010) for the IHME methods. In the case of the Brass method, the appropriate model age pattern of mortality was selected using the underlying WPP data as reference.

Deaths and exposure of children needed for direct estimation of the U5MR were also extracted and summed after each replication. This was carried out using the recorded dates of births and deaths as with FBH data. Period-specific estimates were computed using the synthetic cohort method described by Hill (2013a). In the absence of data errors, these are unbiased estimates of the WPP input rates. As such, they were used as benchmark to evaluate the magnitude of the deviation of the indirect estimates from "true" parameters ${ }^{11}$.

However, the simulated WPP rates should not be considered exact replicas of the

15-19), whereas an increase could result from higher concentration of early childbearing among an increasingly disadvantaged group.

${ }^{11}$ The relative difference between the direct and indirect U5MR estimates was calculated for each time reference generated by the indirect methods. Following the notation of Silva (2012), the relative difference is defined as 
actual demographic trends experienced by countries. They are themselves smoothed estimates based on defective data, including SBHs (Gerland 2014; UN 2014b). Nonetheless, the purpose of using these rates is simply to examine comparatively the performance of the SBH methods in a range of known demographic regimes ${ }^{12}$.

\section{Results}

\subsection{Maternal age variants}

To estimate under-five mortality from past censuses, users are limited to SBHs classified by maternal age. As a result, they will have the option of applying only three of the six methods under study: the Brass-MA and IHME-MAC and -MAP methods. The Brass-MA and IHME-MAC methods use the same cohort data aggregated by five-year group of mothers. The IHME-MAP method uses a special tabulation of women classified by two-year age group and number of CD/CEB. If microdata are available to compute this nonstandard tabulation, Rajaratnam et al. (2010) recommend using the IHME-MAP method in combination with the IHME-MAC method. If only standard five-year aggregated data are available, the authors suggest using only the IHME-MAC method.

(1) The cohort-derived Brass-MA and IHME-MAC methods and (2) the combination of IHME-MAC and -MAP methods are analyzed separately in the next two sections.

\subsubsection{Cohort-derived methods: Brass vs. IHME}

Figure 3 summarizes the relative deviation from benchmark of the U5MR estimates produced by the Brass-MA and IHME-MAC methods across world region. The median of the deviation is represented over time, while the bands cover the maximum and minimum deviations observed ${ }^{13}$. The diamonds correspond to the mean values. The grey lines delimit an upper and lower 10\% deviation interval. Numeric results as well as individual plots for each country are shown in Appendix D.

$d_{i}=\frac{\hat{x}_{i \text {,indirect }}-\hat{x}_{i \text {,direct }}}{\hat{x}_{i, \text { direct }}}$ where $\hat{x}_{i \text {, direct }}$ and $\hat{x}_{i \text {,indirect }}$ are the estimates derived respectively from the direct and indirect methods for the $i$-th year prior to data collection.

12 This is as previous works have done when evaluating selection biases in the estimation of adult mortality from sibling survival information (Bergouignan 2010; Masquelier 2012).

${ }^{13}$ Figure 3 does not show the outliers detected using the Tukey (1977) rule, that is if the observation is higher than $\mathrm{Q} 3+1.5(\mathrm{Q} 3-\mathrm{Q} 1)$ or smaller than $\mathrm{Q} 1-1.5(\mathrm{Q} 3-\mathrm{Q} 1)$, where $\mathrm{Q} 1$ and $\mathrm{Q} 3$ are the first and third quartiles. 
Verhulst: Child mortality estimation

Figure 3: $\quad$ Relative deviation from benchmark of the under-five mortality rate estimates generated by the maternal age variant of the cohort-derived methods over time and across world regions

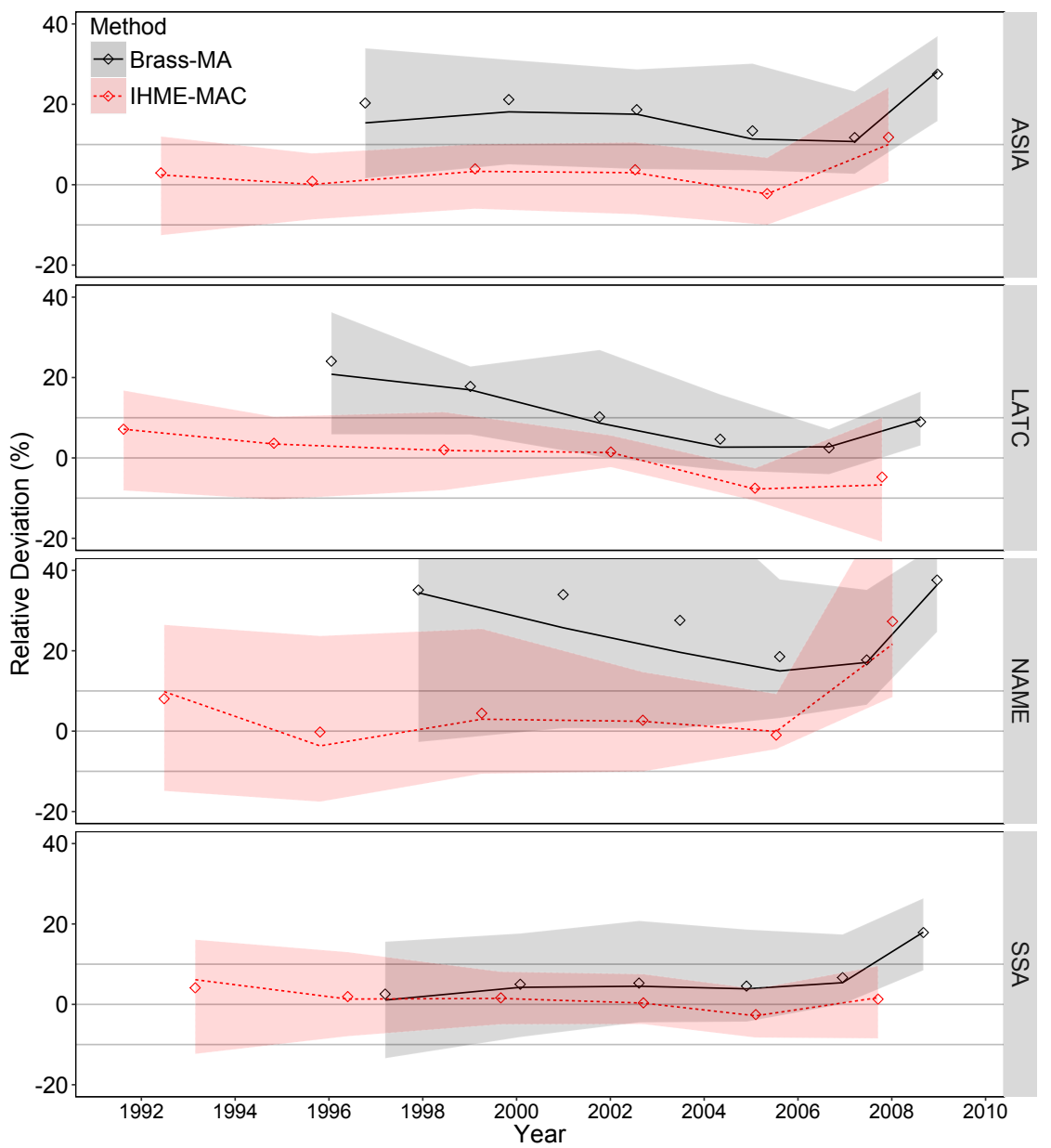

Note: The curves represent the median and the diamonds indicate the mean. The bands cover the maximum and minimum deviations observed. The grey lines delimit an upper and lower $10 \%$ deviation interval. Regions are Asia (ASIA), Latin America and the Caribbean (LATC), Northern Africa and the Middle-East (NAME), and Sub-Saharan Africa (SSA). 
Estimates are associated with mothers aged 20-24 to 45-49. The first estimate on the right (the most recent) is associated with age group $20-24^{14}$ and situated slightly further than two years prior to data collection (end of 2010) for the Brass-MA method. The IHME-MAC estimates are situated further back in the past and cover larger periods of time than the Brass-MA ones. For example, the second estimate is situated on average six years prior to data collection, the same as for the third estimate generated by the BrassMA method. This is because the IHME-MAC estimates are better situated over time as the results prove.

Indeed, except for the first estimate, the IHME-MAC method shows good performance across world regions with an average deviation from benchmark close to zero. The method is particularly robust for the second, third and fourth estimates (associated with age groups 25-29 to 35-39) situated between six and 12 years prior to data collection, with about $90 \%$ of estimates within a $10 \%$ deviation interval. The older estimates accumulate the experience of older birth cohorts over longer periods of time, and consequently, are a bit noisier.

On the other hand, the Brass-MA method contrasts with an uniform and positive overestimation growing through older cohorts up to $20 \%$ on average for all regions. The Brass estimate based on reports from women aged 30-34 (third on the plot), usually considered the most robust, is overestimated on average by $10 \%$. The single comparison of Brass estimates from the 1970 census of Belgium with official life table values derived from the vital registration system, carried out by Hill (1984), shows differences that fit within the range of magnitude observed from the simulations (respectively for age groups $30-34$ and $45-49$, slightly more than $10 \%$ and a bit less than $20 \%$ ).

The first Brass-MA estimate, associated with women aged 20-24, tend to be upward biased because of the persistent effect of excess mortality associated with young mothers. Although children born to women aged 20-24 do not experience excess mortality themselves (see Figure 2), birth cohorts associated with this age group still reflect the mortality experienced earlier when mothers were aged 15-19. This bias tends to be offset through older cohorts, but has still a potential impact on past estimates. Although the IHME-MAC method tends to control better for this bias, the first recent estimate is still subject to important deviations.

The improved results obtained with the IHME-MAC method, in comparison with the Brass-MA method, stem from the different way these methods capture children's exposure to mortality. On the one hand, the Brass method is based on simulation of stable populations, and thus is exposed to simplifying assumptions on fertility and mortality. Notably, the declining fertility ongoing in the developing world distorts the parity ratios $\left(\mathrm{P}_{15-19} / \mathrm{P}_{20-24}\right.$ and $\left.\mathrm{P}_{20-24} / \mathrm{P}_{25-29}\right)$, which generates an underestimation of the lengths of exposure. As explained by Hill (2013a, p. 163):

\footnotetext{
14 The more recent estimate associated with age group 15-19 was excluded from the analysis due to known upward biases as mentioned earlier.
} 
Verhulst: Child mortality estimation

The parity ratios as observed at the time of the survey [are used] to reflect the time distribution of births in the past. [...] Iffertility is declining [...], the parities for the younger women will be lower and those for the older women higher, reducing the parity ratios below the values for any true cohort. This will give the appearance of more recent childbearing (and thus lower average duration of child exposure to the risk of dying) than is really the case, and thus lead to over-estimates of child mortality.

That explains partly why deviation tends to be lower in Sub-Saharan countries (SSA), given the lower rates of decline than in other regions. Correction of this bias is rather limited. For example, Silva (2012) showed that using true cohort parities available from FBHs could improve the estimates. However, when FBH data are available to do so, there is little advantage to use indirect estimates over direct ones. Furthermore, departures from the linear mortality change assumption have potentially a stronger impact on the Brass estimates (evidence is given in Appendix C).

On the other hand, the IHME-MAC method uses country random effects models to capture exposure in real data collected in diverse demographic contexts. In this case, deviation from benchmark is expected to be random. Good Performance across world region is a good indicator of the validity of such assumption. Indeed, excluding the first estimate, none of the regions is subject to significant systematic errors. However, results for Northern Africa and the Middle-East (NAME) show more variability. This is also the region where the Brass method is the most biased, and therefore where departure from stability is the strongest. The higher variability of the IHME-MAC estimates is likely due to the smallest number of DHS surveys collected in this region, and thus included in the modeling (20 out of 166 surveys).

Finally, it should be noted that, starting from the second estimate, random effects have almost no impact, evidencing no need for national or regional adjustment of the model. Therefore, one could conclude that the IHME-MAC method produces rather robust past trends throughout a variety of demographic transition stages, and as such should be generalizable at the subnational levels and for population subgroups.

\subsubsection{Period-derived method and combination}

The main innovation brought by Rajaratnam et al. (2010) concerns the period-derived method which produces 25-year trends from the time of data collection. However, this method is not expected to be used solely. Rajaratnam et al. (2010) proposed creating a summary measure applying a loess regression to all estimates generated by the four IHME methods (IHME-MAC, -MAP, -TFBC and -TFBP). Similarly to the period-derived method, the combined method produces 25 -year trends. This method is considered to 
perform best. However, when data on first birth is not avaible to generate the total combination, the authors suggest combining the maternal age variants only (IHME-MAP with -MAC methods ${ }^{15}$ ).

As shown in Figure 4, this maternal age combined method tends to produce rather mixed results. The overall deviation is rather good with an average close to zero. However, the most robust estimates tend to be situated in the middle of the trends. Recent estimates tend to be too high or too low (over and under 10\% on average for the two first estimates). Moreover, the variability of deviation is higher than with the single cohortderived method. In particular, the recent estimates are subject to high uncertainty (up to $40 \%$ of error for the two first years prior to data collection).

Furthermore, users must keep in mind that the combined method is dependent upon one critical assumption underlying the IHME-MAP method. This is that within a given region, the time distribution of births and deaths of women in a given two-year age group and with a given number of $\mathrm{CD} / \mathrm{CEB}$ can be generalized across countries and time periods. Because of the disparities in demographic changes within a country, the assumption could be particularly hazardous to make when capturing subnational trends. For illustrative purpose, Figure 5 shows, for each region, the deviation for aggregated five-year period estimates, when using different regional expected time distributions of births and deaths. Countries in Asia and Latin America and the Caribbean (LATC) can easily switch their time distributions without strong distortions in the trends. This is because of their similar stage in the demographic transition. Nonetheless, using the expected time distributions of these world regions in Sub-Saharan (SSA) countries leads to strong overestimation of mortality declines. This misuse of the method is likely to be a concern for the subnational regions of Asia, Latin America and the Caribbean, and Northern Africa and the Middle-East that lag behind in the fertility and mortality decline. Conversely, the combined method is expected to underestimate mortality decline in the most advanced areas of Sub-Saharan Africa (such as urban areas). This warning also applies when estimating mortality for subpopulation groups. For this reason, the single IHME-MAC method should be preferred over the combined one due to its robustness in diverse demographic regimes.

\footnotetext{
$\overline{15}$ Excluding the estimate associated with women aged 15-19 due to its instability (Rajaratnam et al. 2010).
} 
Verhulst: Child mortality estimation

Figure 4: $\quad$ Relative deviation from benchmark of the under-five mortality rate estimates generated by the maternal age variant of the combined IHME method over time and across world regions

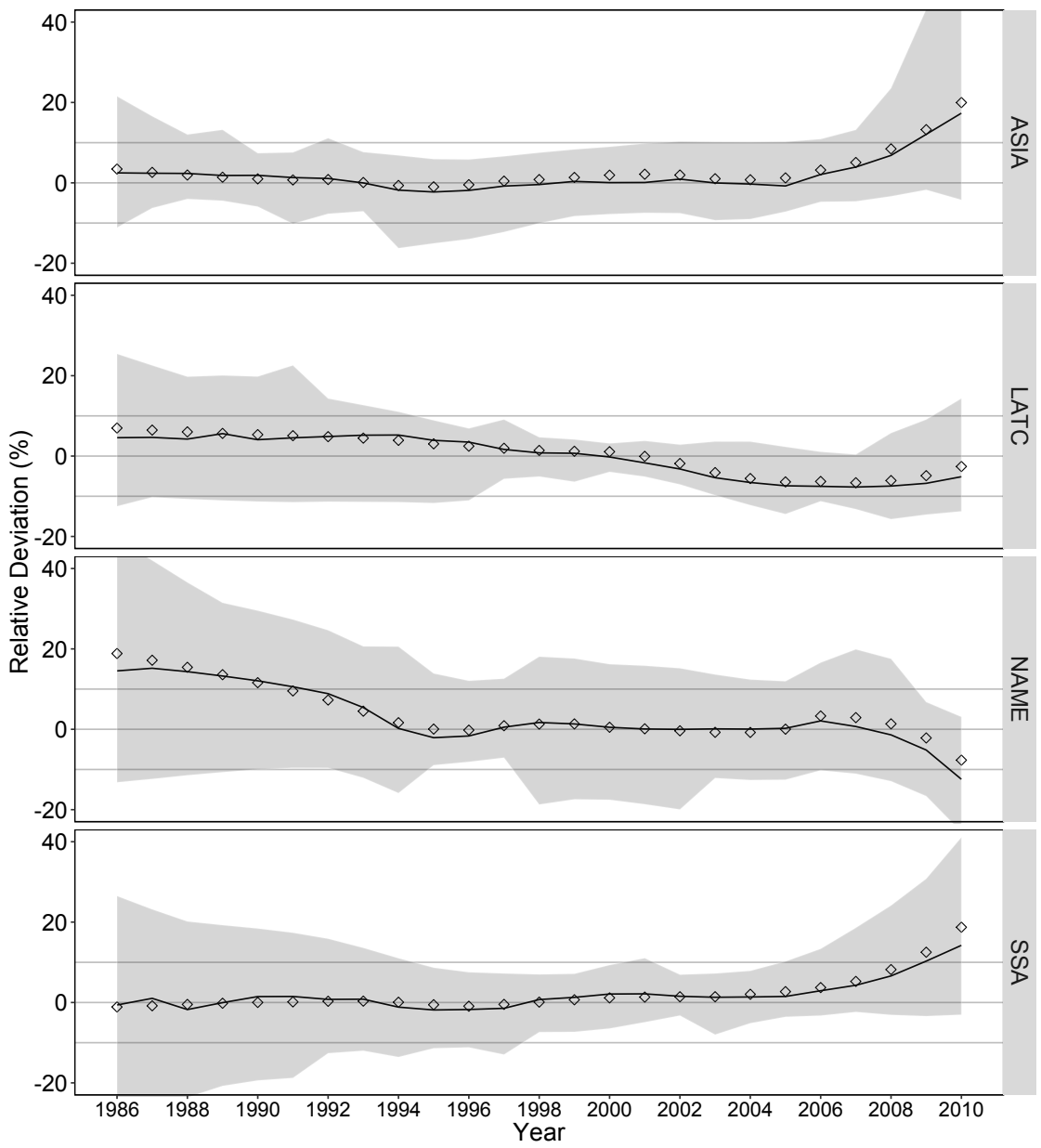

Note: The curves represent the median and the diamonds indicate the mean. The bands cover the maximum and minimum deviations observed. The grey lines delimit an upper and lower $10 \%$ deviation interval. Regions are Asia (ASIA), Latin America and the Caribbean (LATC), Northern Africa and the Middle-East (NAME), and Sub-Saharan Africa (SSA). 
Figure 5: $\quad$ Relative deviation from benchmark of the under-five mortality rate estimates generated by the maternal age variant of the combined IHME method over time and across world regions, using different regional expected time distributions of births and deaths

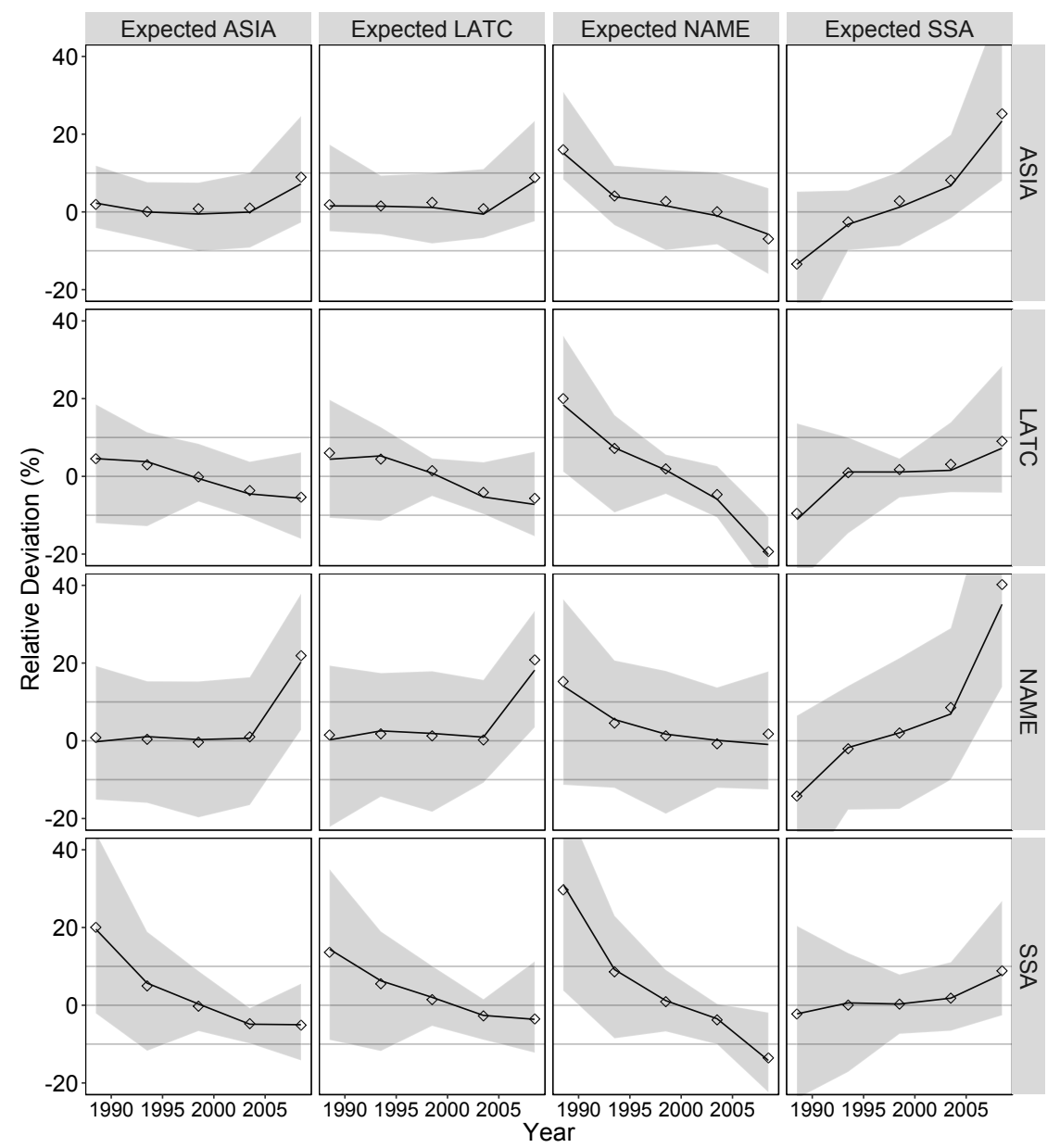

Note: The curves represent the median and the diamonds indicate the mean. The bands cover the maximum and minimum deviations observed. The grey lines delimit an upper and lower $10 \%$ deviation interval. Regions are Asia (ASIA), Latin America and the Caribbean (LATC), Northern Africa and the Middle-East (NAME), and Sub-Saharan Africa (SSA). 


\subsection{Time since first birth variants}

Figure 6 summarizes the results for the time since first birth variant of cohort-derived methods (Brass-TFB and IHME-TFBC) across world regions. The time trends correspond to the estimates associated with duration groups $0-4$ (first on the right and situated on average two years prior to data collection) to 20-24. For IHME-TFBC method, additional results (more unstable) for duration groups 25-29 and 30-34 are shown in Appendix D.

For the Brass-TFB method, the most recent estimate is affected by an upward bias up to $10 \%$. This bias is smaller than for the recent estimate based on age group 2024 , but still reflects the excess mortality associated with young mothers. The IHMETFBC estimates are slightly better on average, but they are far more noisy. However, these results should be taken with caution. In the real world, the mortality risk varies not only with maternal age but also with birth order, which was not simulated and to which the variant is potentially vulnerable. First births are usually considered at higher risk compared to higher-order births (Hill 2013b), and thus the overestimation could be greater than observed in the simulations. However, this potential upward effect could also be offset by lower mortality risks for higher-order children born within the five years since first birth.

For estimates situated further in the past, both methods outperform their maternal age counterpart and show higher stability across regions. For the Brass-TFB method, more than $90 \%$ of estimates associated with duration groups 5-9 and 10-14 (second and third on the plot) fall within a $10 \%$ deviation interval. The IHME-TFBC method produces similar average trends than the IHME-MAC method but with less uncertainty.

This higher performance over the maternal variant is likely due to the way it captures the time distribution of past births through parity ratios. As explained earlier, with the age variant, when fertility is declining the parity ratios are distorted giving the appearance of a shorter time exposure. With the time since first birth variant, Hill (2013b) suggested that the parity ratios tend to be more stable over time. Hence, this duration variant would control, to some extent, for the fertility decline. Nonetheless, the Brass-TFB method is still subject to some important upward biases for estimates situated further back in time, which is also attributable to non-linear changes in mortality (see in Appendix C). In the case of the IHME-TFBC method, although the maternal age variant was already designed to control for fertility decline, the stability of the parity ratios over time seems to bring even more robustness to the estimates.

Lastly, as reported in Appendix D, neither the time since first birth variant of the combined method (IHME-TFBC and -TFBP) nor the full combination of the four IHME methods outperform the simple maternal age variant combination (IHME-MAC and MAP) discussed earlier. As a consequence, these other combined methods should be discarded as well. 
Figure 6: $\quad$ Relative deviation from benchmark of the under-five mortality rate estimates generated by the time since first birth variant of the cohort-derived methods over time and across world regions

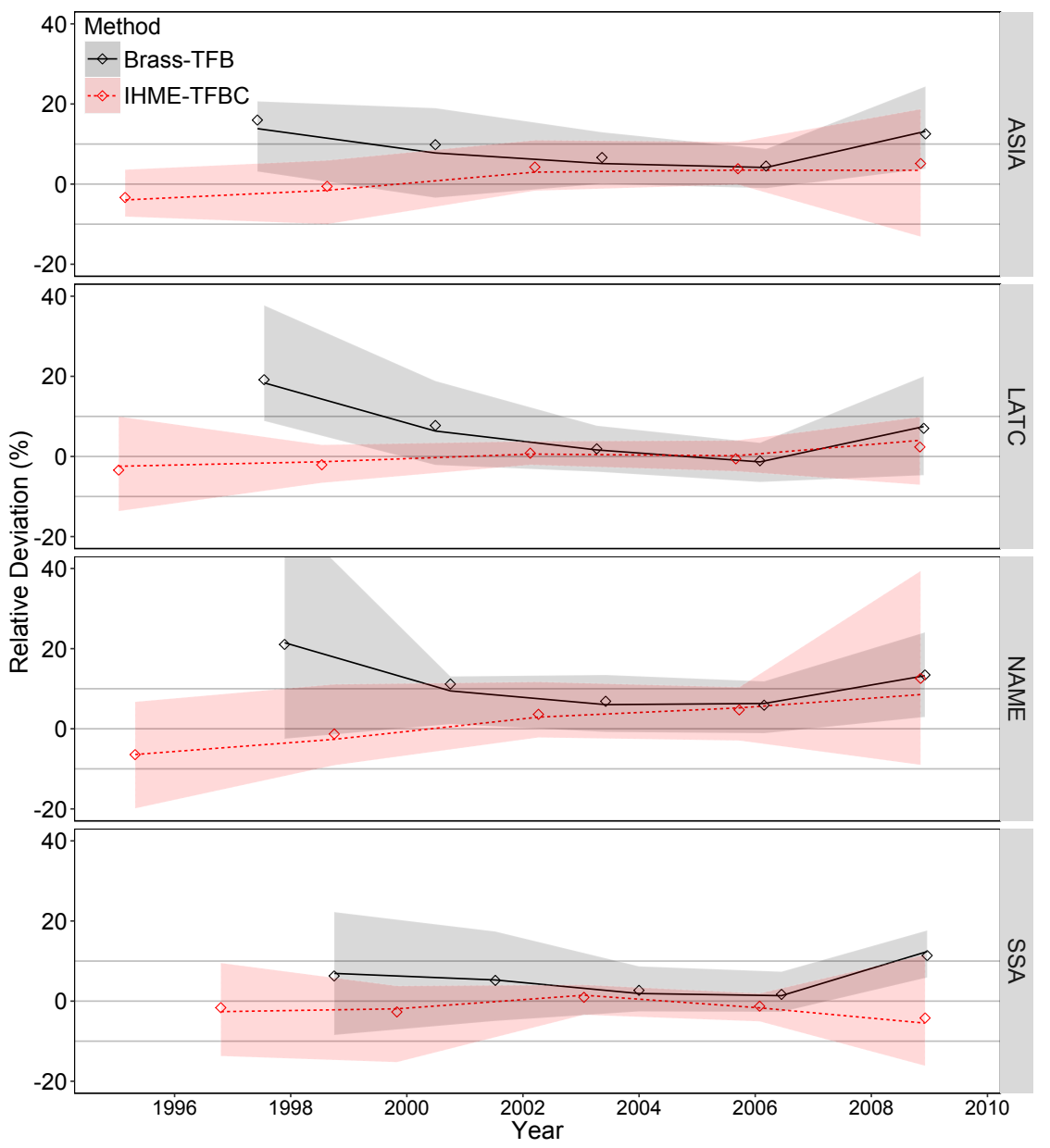

Note: The curves represent the median and the diamonds indicate the mean. The bands cover the maximum and minimum deviations observed. The grey lines delimit an upper and lower $10 \%$ deviation interval. Regions are Asia (ASIA), Latin America and the Caribbean (LATC), Northern Africa and the Middle-East (NAME), and Sub-Saharan Africa (SSA). 


\section{Discussion}

In this study, six indirect methods for estimating U5MR trends from SBHs were evaluated using microsimulation. These methods belong to two main categories: model-based methods derived from Brass's pioneering work and empirically based methods developed at the IHME. The IHME methods are themselves classified into two categories: a cohortderived method using the same cohort data as the Brass method, and a period-derived method based on regional time distributions of births and deaths. Furthermore, both the Brass and IHME methods include two variants depending on the proxy used to capture the exposure to mortality, either maternal age or time since first birth. In order to assess their comparative performance, indirect estimates were compared against benchmark direct estimates, both derived from country-specific simulations. The simulations were generated based on the WPP fertility and mortality rates for 82 countries reflecting a good diversity of international demographic experience.

The main findings of this study can be summarized as follows: (1) using the same data, the maternal age variant of the IHME cohort-derived method (IHME-MAC) outperforms the standard Brass method (Brass-MA), and is able to produce rather robust past trends across different demographic regimes. However, the IHME-MAC method hardly produces robust estimates within the 5 years prior to data collection. (2) The IHMEMAC method should be preferred over the recommended combinations with other IHME methods. (3) The time since first birth variant of the Brass and cohort-derived IHME methods (Brass-TFB and IHME-TFBC) perform better than their respective maternal age counterparts.

Consequently, when users dispose of SBHs classified by maternal age (as collected in past censuses), this study suggests using the IHME-MAC method. Combination with the IHME-MAP method does not provide additional insights. Moreover, this combination relies on the assumption that time distribution of births and deaths can be generalized across space and time, which was shown to be particularly risky when estimation is made at the subnational level (or for specific subpopulation groups).

This study also suggests that the time since first birth variant should be preferred when data are available. From the simulations, the IHME-TFBC method produces longer and more robust trends than any other method. However, for both the Brass and IHME methods, further research is needed to draw sound conclusions as to the performance of this variant. In particular, it would be necessary to take into account the effect of birth order on the mortality risk. Higher risks for first births could lead to an upward bias of the most recent (higher than it appears in the simulations). However, this potential upward effect could also be offset by lower mortality risks for higher-order children born within the five years since first birth. Regardless, considering the lower uncertainy in generating past trends, it would be worthwhile to collect the additional information on date of first 
birth in future censuses (and household surveys), which the United Nations has already recommended for the 2020 census round (UN 2015).

Other biases and errors that may exist in the real word were not simulated in this study, including: (1) selection biases due to association between child mortality and mother survival, and (2) sampling and non-sampling errors that may affect the data prior to the application of SBH methods. Reasoned speculations as to the direction and magnitude of these biases and errors are as follows.

Firstly, selection biases would underestimate the U5MRs. When data are collected retrospectively, children whose mothers are deceased (or absent) are not captured. These children that are not captured are usually considered at higher risk of dying (Hill 2013c). Strong association between child and mother mortality has been related to the vertical transmission of HIV from mother to child in generalized epidemic context (Walker, Hill, and Zhao 2012). However, in low HIV-prevalence contexts (less than 5\%), the bias is no expected to have a strong impact on indirect estimates ${ }^{16}$.

Secondly, data errors can bias indirect estimates either downward or upward. However, such errors are particularly difficult to identify without a gold-standard reference. Concerning non-sampling errors (e.g., age misreporting, omissions of births, etc.), existing data quality assessment techniques are rudimentary and hardly inform the magnitude of errors ${ }^{17}$. Estimates derived from declarations of women older than 39 years old are generally considered more vulnerable to recall errors (Silva 2012). Such errors are usually considered modest among younger women. However, further work is needed to develop better data quality diagnostics for SBHs collected in censuses and surveys.

Finally, we end referring to recent developments on mortality estimation based on massive datasets such as those of the UN IGME, Global Burden of Disease (GBD) Study, and Latin American Mortality Database (LAMBdA). Instead of choosing a single mortality estimate among several existing ones for a single year, these projects consider all available estimates taking their inherent uncertainty/bias into account. The idea is to blend redundant estimates derived from the application of different estimation methods on multiple datasets and to associate each of these either with fixed effect biases according to the data source (Alkema and New 2014; Wang and al. 2014) or with a level of uncertainty reflecting the probability that underlying assumptions are violated under a particular set of conditions (Palloni and Beltrán-Sánchez 2016). Thus, the results of our study, and further simulations, might be useful as input to these complex estimation procedures that require integration of multiple available data and methods.

\footnotetext{
16 "Drawing on the pattern of bias by HIV prevalence found by Ward and Zaba (2008), the child mortality estimate obtained by standard analysis of a summary birth history could be adjusted upwards by three points per thousand for every 10 percentage points of HIV prevalence" (Hill 2013c, p. 146).

17 These techniques mostly consist of examining age heaping, sex ratio, and average number of CD/CEB through age groups or cohorts when succesive data sources are available over time (Hill 2013b).
} 


\section{Acknowledgements}

I especially thank Carl Mason and Bruno Masquelier for their assistance with microsimulation using Socsim. I am grateful to Hiram Beltrán-Sánchez, Patrick Gerland, Bruno Masquelier, Alberto Palloni, Jon Pedersen, Tim Miller, and Bruno Schoumaker for their advice and manuscript reviews. I'm also thankful to Jee Jee Kim for enhancing my writing. Finally, I appreciate the editor and reviewers for helping me to improve this paper. This research was funded with a doctoral fellowship from the Belgian National Fund for Scientific Research (F.R.S.-FNRS).

\section{Corrections:}

On February 28, 2017, 'CEB/CD' was consistently changed to 'CD/CEB' throughout the paper. 


\section{References}

Alkema, L. and New, J. (2014). Global estimation of child mortality using a bayesian b-spline bias-reduction model. The Annals of Applied Statistics 8(4): 2122-2149. doi:10.1214/14-AOAS768.

Bergouignan, C. (2010). Recourir aux microsimulations pour dier la mortalit crise : illustration par la mortalit Burundi en 1993. Cahiers qucois de dgraphie 40(2): 299-329. doi:10.7202/1011543ar.

Brass, W. and Coale, A. (1968). Methods of analysis and estimation. In: Brass, W., Coale, A., Demeny, P., Heisel, D., Lorimer, F., Romaniuk, A., and van de Walle, E. (eds.). The demography of tropical africa. Princeton: Princeton University Press: 88-150.

Coale, A., Demeny, P., and Vaughan, B. (1966). Regional model life tables and stable populations. Princeton: Princeton University Press.

Collumbien, M. and Sloggett, A. (2001). Adjustment methods for bias in the indirect childhood mortality estimates. In: Zaba, B. and Blacker, J. (eds.). Brass tacks: Essays in medical demography. London: Athlone Press: 20-42.

Cox, D. (1972). Regression models and life-tables. Journal of the Royal Statistical Society. Series B (Methodological) 34(2): 187-220.

Feeney, G. (1980). Estimating infant mortality trends from child survivorship data. Population Studies 34(1): 109-128. doi:10.2307/2173698.

Fernandez, R. (1985). The influence of differentials in child mortality by age of the mother, birth order, and birth spacing on indirect estimation methods. [PhD Thesis]. London School of Hygiene and Tropical Medicine.

Gerland, P. (2014). UN Population Division's methodology in preparing base population for projections: Case study for India. Asian Population Studies 10(3): 274-303. doi:10.1080/17441730.2014.947059.

Hammel, E., Hutchinson, D., Wachter, K., Lundry, R., and Deuel, R. (1976). The socsim demographic-sociological microsimulation program: Operating manual. Institute of International Studies, UC Berkeley. Research series 27.

Heligman, L. and Pollard, J. (1980). The age pattern of mortality. Journal of the Institute of Actuaries 107(434): 49-80. doi:10.1080/17441730.2014.947059.

Hill, K. (1984). An evaluation of indirect methods for estimating mortality. In: Vallin, J., Pollard, J., and Heligman, L. (eds.). Methodologies for the collection and analysis of mortality data. Li: Odina Editions: 145-176.

Hill, K. (2013a). Direct estimation of child mortality from birth histories. In: Moultrie, 
T., Dorrington, R., Hill, A., Hill, K., Tim, I., and Zaba, B. (eds.). Tools for demographic estimation. Paris: International Union for the Scientific Study of Population: 166-177.

Hill, K. (2013b). Indirect estimation of child mortality. In: Moultrie, T., Dorrington, R., Hill, A., Hill, K., Tim, I., and Zaba, B. (eds.). Tools for demographic estimation. Paris: International Union for the Scientific Study of Population: 148-164.

Hill, K. (2013c). Introduction to child mortality analysis. In: Moultrie, T., Dorrington, R., Hill, A., Hill, K., Tim, I., and Zaba, B. (eds.). Tools for demographic estimation. Paris: International Union for the Scientific Study of Population: 141-146.

Hill, K. and Figueroa, M.E. (2001). Child mortality by time since first birth. In: Zaba, B. and Blacker, J. (eds.). Brass tacks: Essays in medical demography. London: Athlone Press: 9-19.

Hill, K., You, D., Inoue, M., Oestergaard, M., and TAG (2012). Child mortality estimation: accelerated progress in reducing global child mortality, 1990-2010. PLoS Med 9(8): e1001303. doi:10.1371/journal.pmed.1001303.

Mason, C. (2013). Socsim oversimplified. [electronic resource]. Department of Demography, UC Berkeley. Consulted on May 1, 2015. http://lab.demog.berkeley.edu/socsim/CurrentDocs/socsimOversimplified.pdf.

Mason, C. (2014). Demographic models. In: O'Donoghue, C. (ed.). Handbook of microsimulation modelling. Bradford: Emerald Group Publishing: 345-365.

Masquelier, B. (2012). Adult mortality from sibling survival data: A reappraisal of selection biases. Demography 50(1): 207-228. doi:10.1007/s13524-012-0149-1.

Palloni, A. and Beltrán-Sánchez, H. (2016). Uncertainty and mortality estimates in Latin American and Caribbean (LAC) region: 1850-2010. Paper presented at Population Association of America Meeting, Washington DC, March 31 - April 2.

Preston, S., Heuveline, P., and Guillot, M. (2001). Demography. Measuring and modeling population processes. Oxford: Wiley-Blackwell.

Rajaratnam, J., Tran, L., Lopez, A., and Murray, C. (2010). Measuring underfive mortality: Validation of new low-cost methods. PLoS Med 7(4): e1000253. doi:10.1371/journal.pmed.1000253.

Schmertmann, C. (2012). Calibrated spline estimation of detailed fertility schedules from abridged data. Rostock: Max Planck Institute for Demographic Research. (MPIDR working paper, WP-2012-022).

Silva, R. (2012). Child mortality estimation: Consistency of under-five mortality rate estimates using full birth histories and summary birth histories. PLoS Med 9(8): e1001296. doi:10.1371/journal.pmed.1001296. 
Sullivan, J. (1972). Models for the estimation of the probability of dying between birth and exact ages of early childhood. Population Studies 26(1): 79-97.

Trussell, J. (1975). A re-estimation of the multiplying factors for the Brass technique for determining childhood survivorship rates. Population Studies 29(1): 97-107.

Tukey, J. (1977). Exploratory data analysis. Don Mills: Addison-Wesley Publishing Company.

UN (1983). Manual X: Indirect techniques for demographic estimation. New York: United Nations.

UN (2013a). Implementation of united nations recommendations for population census topics in the 2010 round. New York: Statistic Division, Economic and Social Affairs. United Nations Expert Group Meeting on revising the principles and recommendations for population and housing censuses, New York, October 31 - November 1.

UN (2013b). Mortpak for windows (version 4.3). New York: Population Division, Economic and Social Affairs.

UN (2014a). Coverage of birth and death registration. [electronic resource]. Statistic Division, Economic and Social Affairs. Consulted on November 1, 2014. URL http://unstats.un.org/unsd/demographic/CRVS/CR_coverage.htm.

UN (2014b). World population prospects: The 2012 revision - methodology of the united nations population estimates and projections. New York: Population Division, Economic and Social Affairs.

UN (2015). Principles and recommendations for population and housing censuses: the 2020 round (revision 3 - draft). New York: Statistical Commission, Economic and Social Affairs. Forty-sixth session, 3 - 6 March.

UNICEF (2015). A post-2015 world fit for children. a review of the open working group report on Sustainable Development Goals from a child rights perspective. [electronic resource]. Consulted on May 1, 2016. http://www.unicef.org/post2015/files/Post_2015_OWG_review_CR_FINAL.pdf.

Van Imhoff, E. and Post, W. (1998). Microsimulation methods for population projections. Population: An English Selection (Special Issue) 10: 97-138.

Walker, N., Hill, K., and Zhao, F. (2012). Child mortality estimation: Methods used to adjust for bias due to AIDS in estimating trends in under-five mortality. PLoS Med 9(8): e1001298. doi:10.1371/journal.pmed.1001298.

Wang, H. and al. (2014). Global, regional, and national levels of neonatal, infant, and under-5 mortality during 1990-2013: a systematic analysis for the global burden of disease study 2013. The Lancet 384(9947): 957-979. doi:10.1016/S0140- 
6736(14)60497-9.

Ward, P. and Zaba, B. (2008). The effect of HIV on the estimation of child mortality using the children surviving/children ever born technique. Southern African Journal of Demography 11(1): 39-73.

Zimmerman, L. (2014). Under-5 mortality estimation in humanitarian emergencies: A comparison of estimation methodologies using microsimulation. [PhD Thesis]. Baltimore: Johns Hopkins University. 


\section{Appendices}

\section{A Microsimulation inputs}

\section{United Nations' World Population Prospects}

Below is a list of the 82 selected countries for which the WPP fertility and mortality rates were simulated:

\begin{tabular}{|c|c|c|c|}
\hline Asia & $\begin{array}{l}\text { Latin America and } \\
\text { the Caribbean }\end{array}$ & $\begin{array}{l}\text { Northern Africa and } \\
\text { the Middle-East }\end{array}$ & $\begin{array}{l}\text { Sub-saharan } \\
\text { Africa }\end{array}$ \\
\hline $\begin{array}{l}\text { Afghanistan } \\
\text { Bangladesh } \\
\text { Bhutan } \\
\text { Burma } \\
\text { Cambodia } \\
\text { India } \\
\text { Indonesia } \\
\text { Kazakhstan } \\
\text { Kyrgyz Republic } \\
\text { Lao } \\
\text { Mongolia } \\
\text { Nepal } \\
\text { Pakistan } \\
\text { Philippines } \\
\text { Tajikistan } \\
\text { Thailand } \\
\text { Timor-Leste } \\
\text { Turkmenistan } \\
\text { Uzbekistan } \\
\text { Vietnam }\end{array}$ & $\begin{array}{l}\text { Bolivia } \\
\text { Brazil } \\
\text { Colombia } \\
\text { Dominican Republic } \\
\text { Ecuador } \\
\text { El Salvador } \\
\text { Guatemala } \\
\text { Guyana } \\
\text { Haiti } \\
\text { Honduras } \\
\text { Jamaica } \\
\text { Mexico } \\
\text { Nicaragua } \\
\text { Panama } \\
\text { Paraguay } \\
\text { Peru } \\
\text { Suriname } \\
\text { Uruguay } \\
\text { Venezuela }\end{array}$ & $\begin{array}{l}\text { Algeria } \\
\text { Armenia } \\
\text { Azerbaijan } \\
\text { Georgia } \\
\text { Iran } \\
\text { Iraq } \\
\text { Jordan } \\
\text { Lebanon } \\
\text { Libya } \\
\text { Morocco } \\
\text { Oman } \\
\text { Palestine } \\
\text { Sudan } \\
\text { Syria } \\
\text { Tunisia } \\
\text { Turkey } \\
\text { Western Sahara } \\
\text { Yemen }\end{array}$ & $\begin{array}{l}\text { Angola } \\
\text { Benin } \\
\text { Burkina Faso } \\
\text { Chad } \\
\text { Comoros } \\
\text { Congo (DRC) } \\
\text { Djibouti } \\
\text { Equatorial Guinea } \\
\text { Eritrea } \\
\text { Ethiopia } \\
\text { Gambia } \\
\text { Ghana } \\
\text { Guinea } \\
\text { Guinea-Bissau } \\
\text { Liberia } \\
\text { Madagascar } \\
\text { Mali } \\
\text { Mauritania } \\
\text { Niger } \\
\text { Nigeria } \\
\text { Senegal } \\
\text { Sierra Leone } \\
\text { Somalia } \\
\text { South Sudan } \\
\text { Togo }\end{array}$ \\
\hline
\end{tabular}

Single year age-specific fertility rates were smoothed from the WPP abridged data using the calibrated spline estimator developed by Schmertmann (2012). The abridged life tables were interpolated only for ages 2,3 , and 4 , to which indirect estimates are sensitive, using the ICM application ${ }^{18}$ of the UN's MORTPAK software package (UN 2013b). The fertility rates and the logarithms of the central rates of mortality, published

\footnotetext{
18 The ICM application of the UN MORTPAK software package is derived from the first term of the Heligman and Pollard (1980) mortality parametric function.
} 
by five-year period, were then interpolated annually between 1950 and 2010 using natural cubic splines.

\section{Demographic and Health Surveys}

Below is a list of the 135 publicly available standard datasets collected between 1990 and 2013 in 46 of the 82 selected countries for this study. They were used to capture and simulate the variation in infant mortality risk according to the five-year age group of the mother by world region.

\begin{tabular}{ll}
\hline Country & DHS dataset(s) \\
\hline Armenia & $2000,2005,2010$ \\
Azerbaijan & 2006 \\
Bangladesh & $1993,1996,1999$ \\
& $2004,2007,2011$ \\
Benin & $1996,2001,2006$ \\
& 2011 \\
Bolivia & $1994,1998,2003$ \\
& 2008 \\
Brazil & 1991,1996 \\
Burkina Faso & $1993,1998,2003$ \\
& 2010 \\
Burundi & 2010 \\
Cambodia & $2000,2005,2010$ \\
Chad & 1996,2004 \\
Colombia & $1990,1995,2000$ \\
Comoros & 2005,2010 \\
Congo (DRC) & 1996,2011 \\
Dominican Republic & 2007,2013 \\
& $1991,1996,1999$ \\
Ethiopia & $2002,2007,2013$ \\
Ghana & $2000,2005,2011$ \\
& $1993,1998,2003$ \\
Guatemala & 2008 \\
Guinea & 1995 \\
Guyana & $1999,2005,2012$ \\
Haiti & 2009 \\
& $1994,2000,2005$ \\
Honduras & 2012 \\
India & 2005,2011 \\
Indonesia & $1992,1998,2005$ \\
& $1991,1994,1997$ \\
\hline & $2002,2007,2012$ \\
\hline
\end{tabular}

\begin{tabular}{ll}
\hline Country & DHS dataset(s) \\
\hline Jordan & $1990,1997,2002$ \\
& 2007,2012 \\
Kazakhstan & 1995,1999 \\
Kyrgyz Republic & 1997,2012 \\
Liberia & 2007,2013 \\
Madagascar & $1992,1997,2003$ \\
& 2008 \\
Mali & $1995,2001,2006$ \\
& 2012 \\
Morocco & 1992,2003 \\
Nepal & $1996,2001,2006$ \\
& 2011 \\
Nicaragua & 1998,2001 \\
Niger & $1992,1998,2006$ \\
& 2012 \\
Nigeria & $1990,1999,2003$ \\
& 2008,2013 \\
Pakistan & $1990,2006,2012$ \\
Paraguay & 1990 \\
Peru & $1991,1996,2000$ \\
Philippines & $1993,1998,2003$ \\
& 2008,2013 \\
Senegal & $1992,1997,2005$ \\
& 2010 \\
Sierra Leone & 2008,2013 \\
Tajikistan & 2012 \\
Timor-Leste & 2009 \\
Togo & 1998 \\
Turkey & $1993,1998,2003$ \\
Uzbekistan & 1996 \\
Vietnam & 1997,2002 \\
& \\
\hline & \\
\hline
\end{tabular}


In order to capture different models of infant mortality risks accross world regions, a Proportional Hazard Model (Cox 1972) was applied to these DHS datasets . The DHS's individual woman datasets were reshaped so as to obtain each declared birth as a weighted observation, including exposure, survival status, and age of mother at birth. We selected only children with exposure of less than one year, considering that maternal age ceases to have any relevant impact over that age (Fernandez 1985), as well as those born within ten years prior to survey in order to reduce sampling error. The child datasets were then pooled by world region. Following Collumbien and Sloggett (2001), the five-year age group effects were modeled separately with binary covariates in order to get, for each, the relative risk of dying before the age of one year.

\section{B Precision of the microsimulations}

Given the randomness of the microsimulation tool, the simulated mortality and fertility patterns, reflected in the proportions dead of children, can potentially be skewed in the outputs, particularly in conditions of low fertility and mortality. While low fertility regimes tend to reduce the population size, low mortality regimes make vital events much rarer, thus increasing the sampling error. A straightforward way to evaluate the precision of the results is to compare simulated proportions dead of children to theoretical ones calculated analytically for a same stable population.

Theoretical proportions dead of children by age of mother $x, P D(x)$, can be expressed discretely, as follows (Hill 2013b; Preston, Heuveline, and Guillot 2001; Feeney 1980):

$$
P D_{x}=\frac{\sum_{y=\alpha}^{x} f(y)\left(1-{ }_{x-y} L_{0}\right)}{\sum_{y=\alpha}^{x} f(y)}
$$

where $f(y)$ is the fertility rate at age $y, \alpha$ is the earliest age of childbearing, $x$ is the age at the moment of the cross-sectional data collection, and $\left(1-{ }_{x-y} L_{0}\right)$ is the probability of dying by the time of data collection of the corresponding birth cohort. That is proportions dead of children are birth weighted average of cohort probabilities of dying. Under the assumption that the population is stable, theoretical proportions dead of children can be calculated from any set of fertility and mortality rates.

The precision test consists in comparing the simulated and theoretical proportions dead of children in the lowest demographic regimes evaluated in this paper (total fertility 
rate $=2.1$ and $\mathrm{U} 5 \mathrm{MR}=11$ per 1000). Fifteen simulations were run in the same conditions as for the WPP rates ${ }^{19}$ in order to measure the variance of the simulated proportions dead.

Figure below shows the consistency of the simulation outcomes with the expected theoretical reference by single year of age. It shows that, in the lowest demographic conditions studied in this research, the simulated proportions dead of children coincide with sufficient precision with the theoretical ones. The mean deviation from the theoretical proportions dead does not exceed $2 \%$ by five-year group, though the variance of the simulated proportions is a bit higher for women aged 15-19 and 20-24.

It is not possible to check the period proportions dead of children since they are intractable formally. However, being based on declarations of all women (from 15 to 49) at the same time, their variance, under the same demographic regime, should be lower.

Comparison of simulated and expected theoretical proportions dead of children for the lowest demographic regime under study $(T F R=2.1$ and $U 5 M R=11$ per 1000$)$

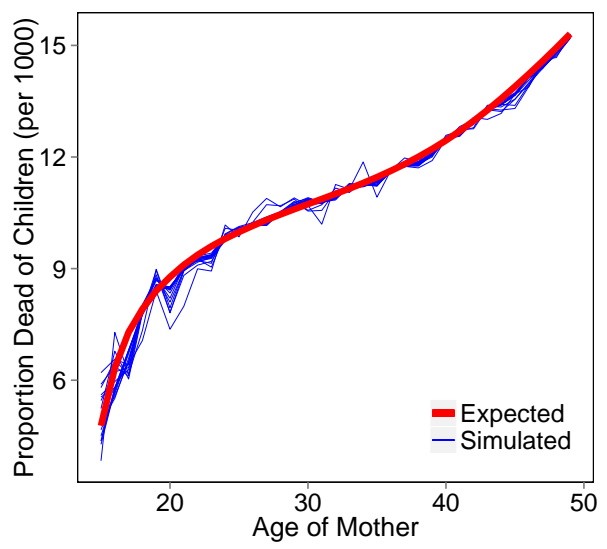

\section{Effect of non-linear mortality change on the Brass method}

The plots above shows that simplifying the assumption on linear mortality change can contribute for a great part in the deviation of the Brass estimates from true parameters.

As shown in the plot $a$, in the mid-1990s, El Salvador experienced a strong deceleration in the mortality decline. From the simulation, the indirect estimate situated the

19 That is with the same initial stable population, duration (60 years) and number of replications (100). 
furthest back in time (associated with women aged 45-49) is approximately 65\% higher than the benchmark, and as such is an outlier among the set of simulations. When mortality decline is linearized between 1985 and 2010 as displayed in plot $b$, the deviation for the same estimate is reduced to $20 \%$.

Comparison with benchmark of the under-five mortality rate estimates generated by the Brass-MA in four fertility and mortality regimes derived from the case of El Salvador
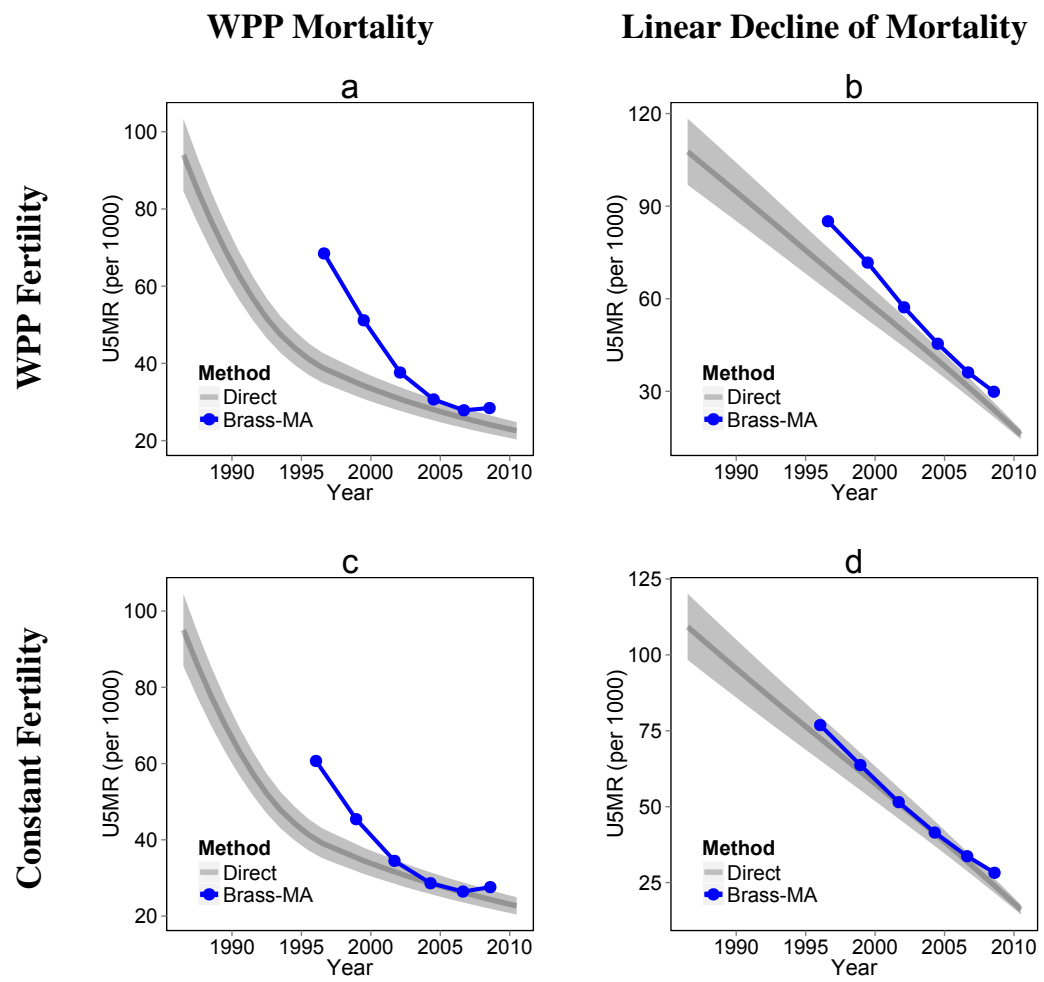

Note: The grey band delimits an upper and lower 10\% deviation interval.

The bias due to non-linear mortality change is associated with the Feeney's timing procedure. When mortality decline is decelerating (convex trend), deaths are more concentrated in the past than under linear assumption. As consequence, the timing procedure allocates the estimates too close to the moment of data collection, which generates an 
overestimation of mortality. Reciprocally, an accelerated decline (concave trend) produces an underestimation.

In the case of El Salvador, departure from linear mortality assumption produces a greater bias than the violation of the constant fertility one. When fertility is fixed to the level of 1985 (see plot $c$ ), the deviation of the estimate situated the furthest back in time is reduced to $45 \%$ only.

Finally, plot $d$ shows that when both assumptions are met, the Brass estimates reproduce the time trend. 


\section{Detailed results}

Numeric results for the cohort-derived methods

\section{Mean deviation from benchmark of the under-five mortality rate estimates gener- ated by the cohort-derived methods}
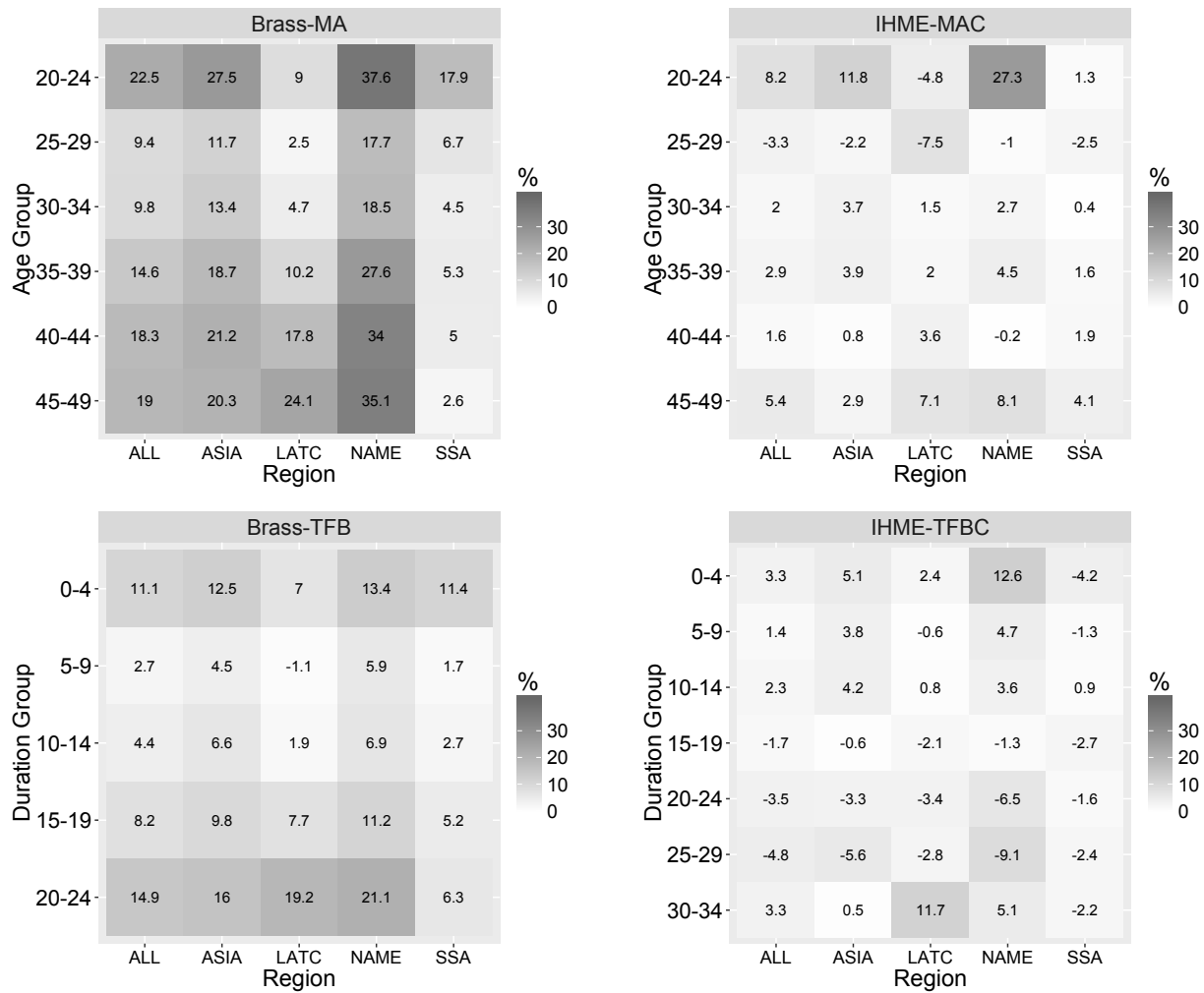

Note: Methods are maternal age and time since first birth variants of the Brass method (Brass-MA and -TFB) and IHME cohort-derived method (IHME-MAC and -TFBC). Regions are Asia (ASIA), Latin America and the Caribbean (LATC), Northern Africa and the Middle-East (NAME), and Sub-Saharan Africa (SSA). 


\section{Percentage of under-five mortality rate estimates generated by the cohort-derived methods within a $10 \%$ deviation interval from benchmark}
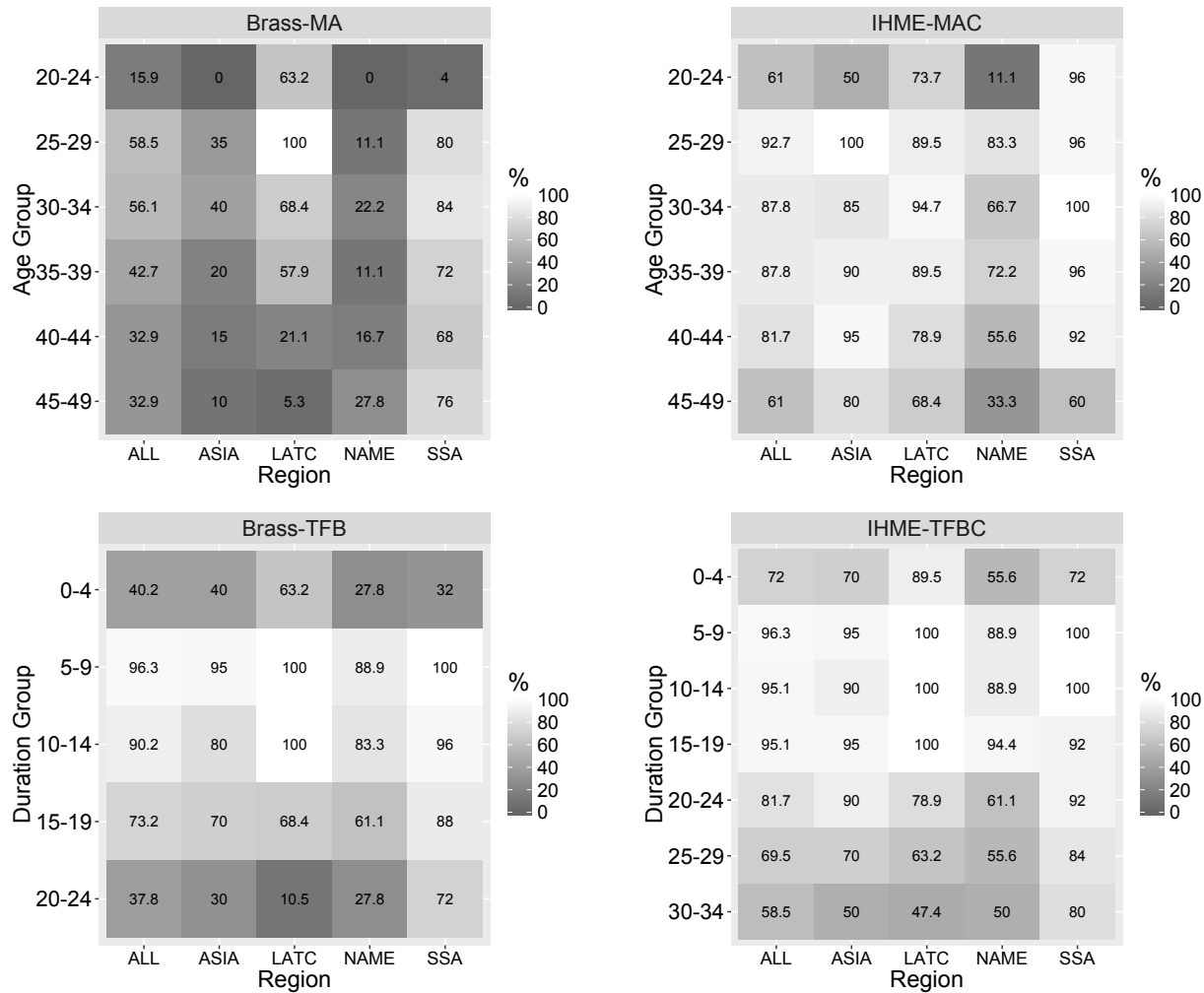

Note: Methods are maternal age and time since first birth variants of the Brass method (Brass-MA and -TFB) and IHME cohort-derived method (IHME-MAC and -TFBC). Regions are Asia (ASIA), Latin America and the Caribbean (LATC), Northern Africa and the Middle-East (NAME), and Sub-Saharan Africa (SSA). 
Numeric results for the combined methods

Mean deviation from benchmark of the under-five mortality rate estimates generated by the combined methods

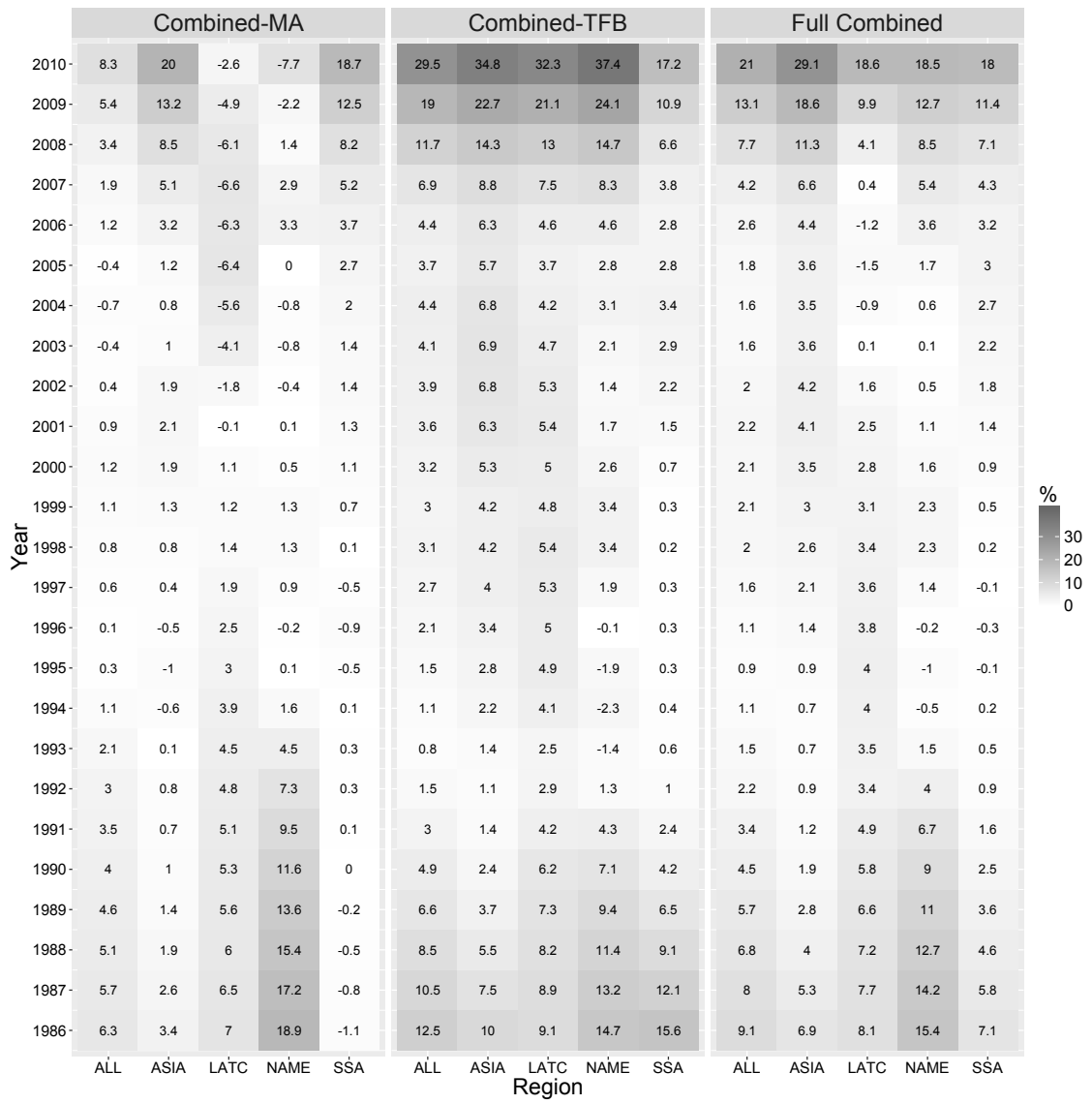

Note: Methods are combination of IHME-MAC and -MAP methods (Combined-MA), IHME-TFBC and -TFB methods (Combined-TFB), and all IHME methods (Full combined). Regions are Asia (ASIA), Latin America and the Caribbean (LATC), Northern Africa and the Middle-East (NAME), and Sub-Saharan Africa (SSA). 
Verhulst: Child mortality estimation

Percentage of under-five mortality rate estimates generated by the combined methods within a $10 \%$ deviation interval from benchmark

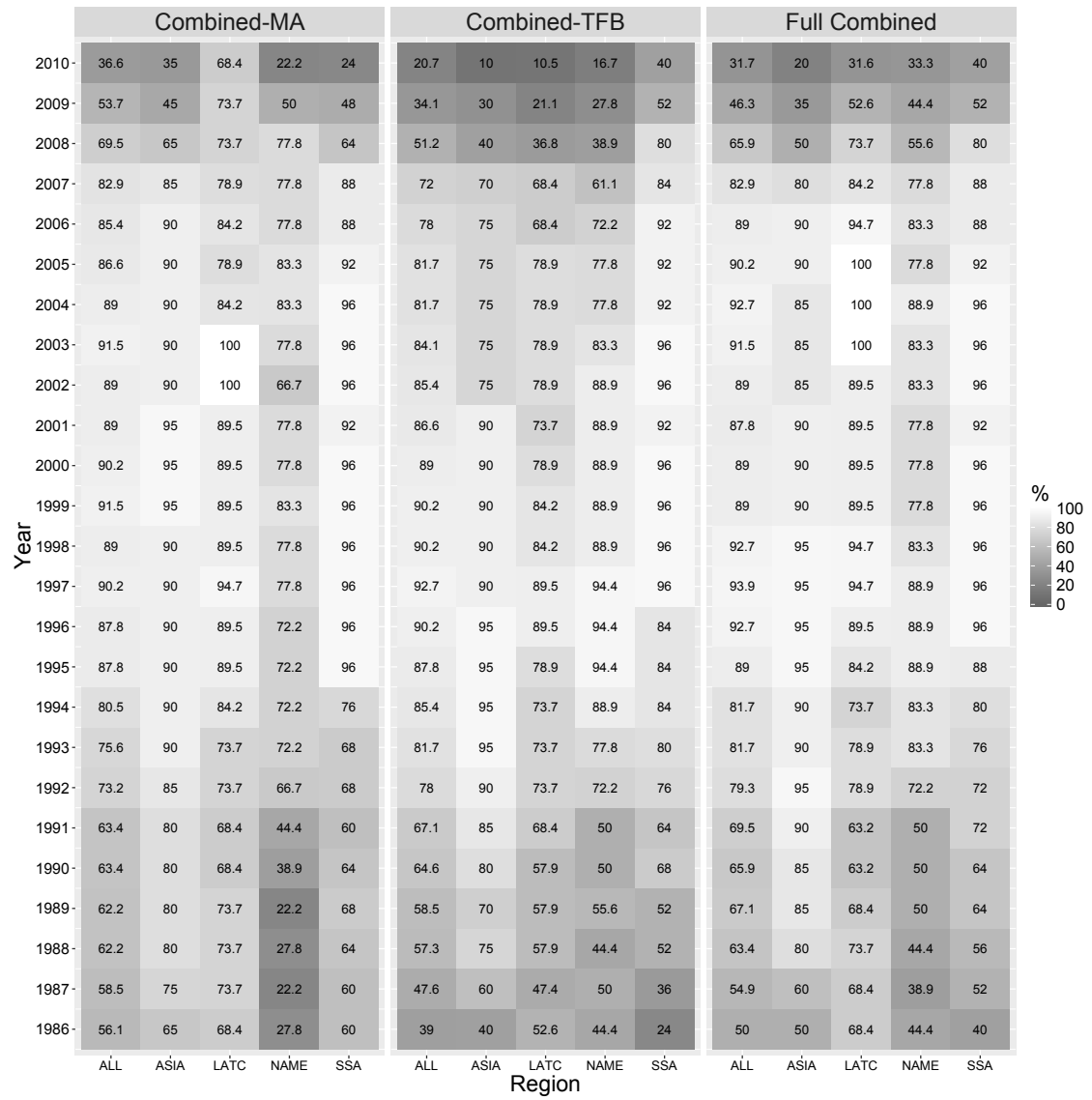

Note: Methods are combination of IHME-MAC and -MAP methods (Combined-MA), IHME-TFBC and -TFB methods (Combined-TFB), and all IHME methods (Full combined). Regions are Asia (ASIA), Latin America and the Caribbean (LATC), Northern Africa and the Middle-East (NAME), and Sub-Saharan Africa (SSA). 


\section{Country plots}

\section{Comparison with benchmark of the under-five mortality rate estimates generated by the maternal age summary birth history methods}

Notes: The grey band delimits an upper and lower 10\% deviation interval.
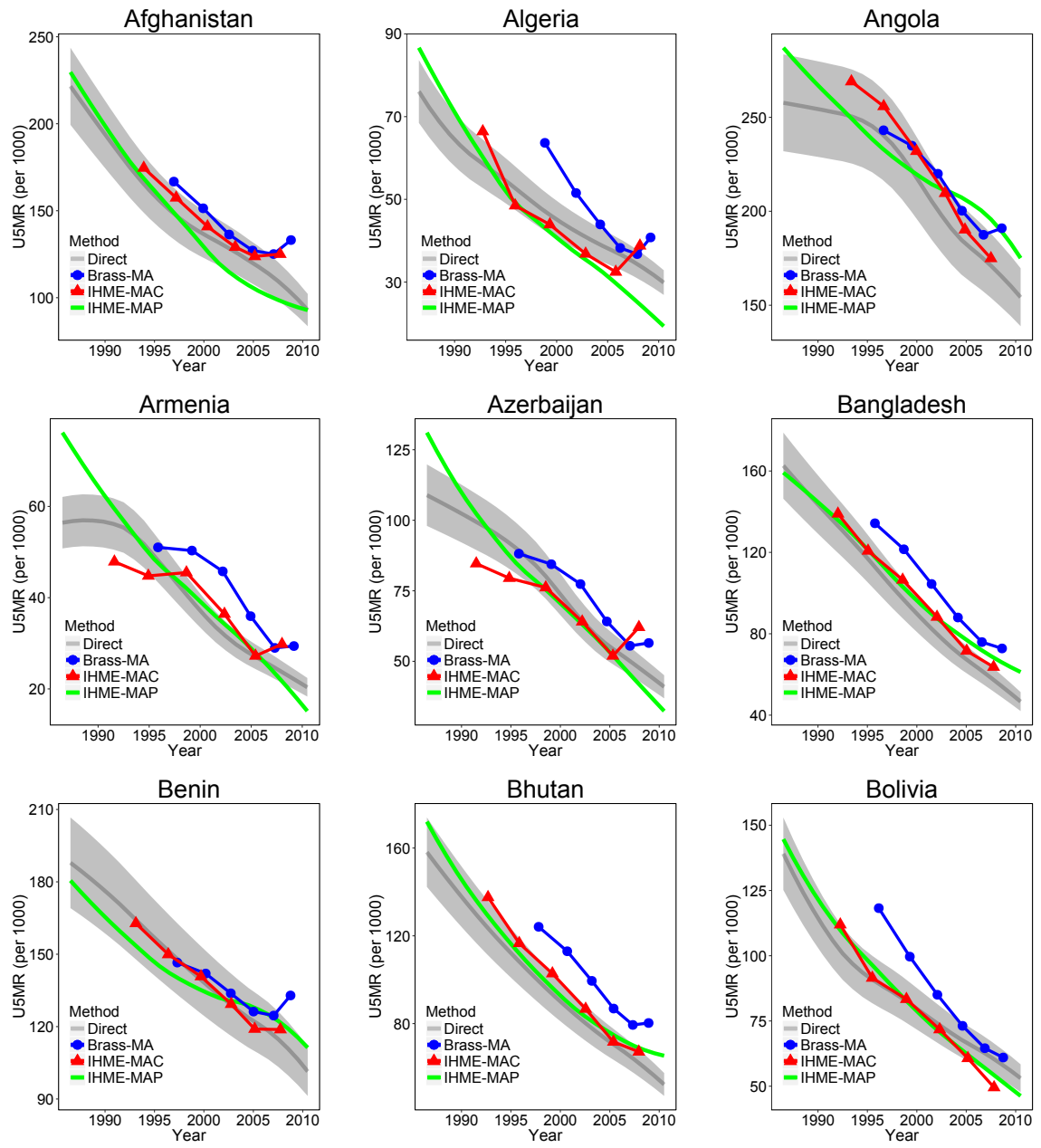

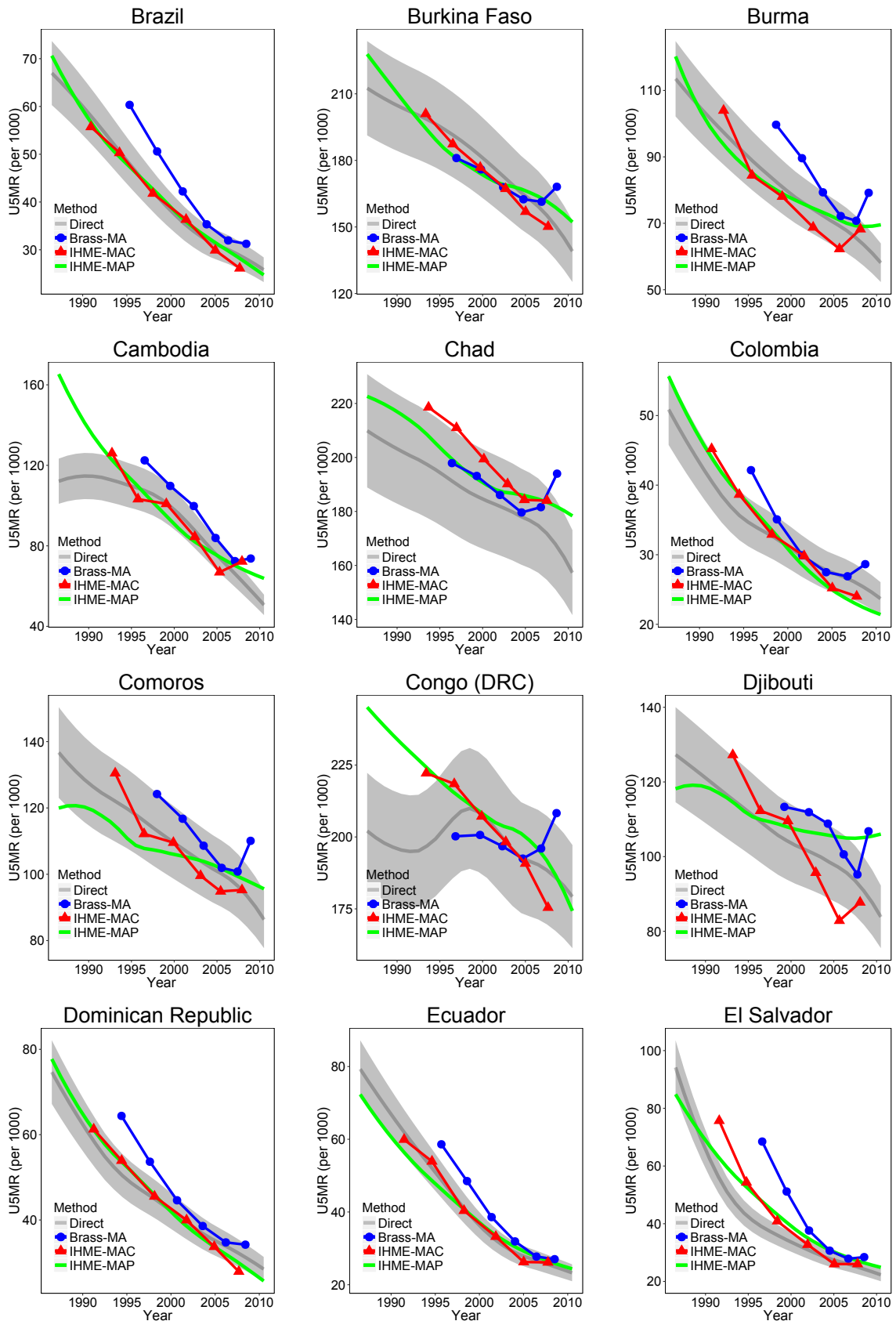

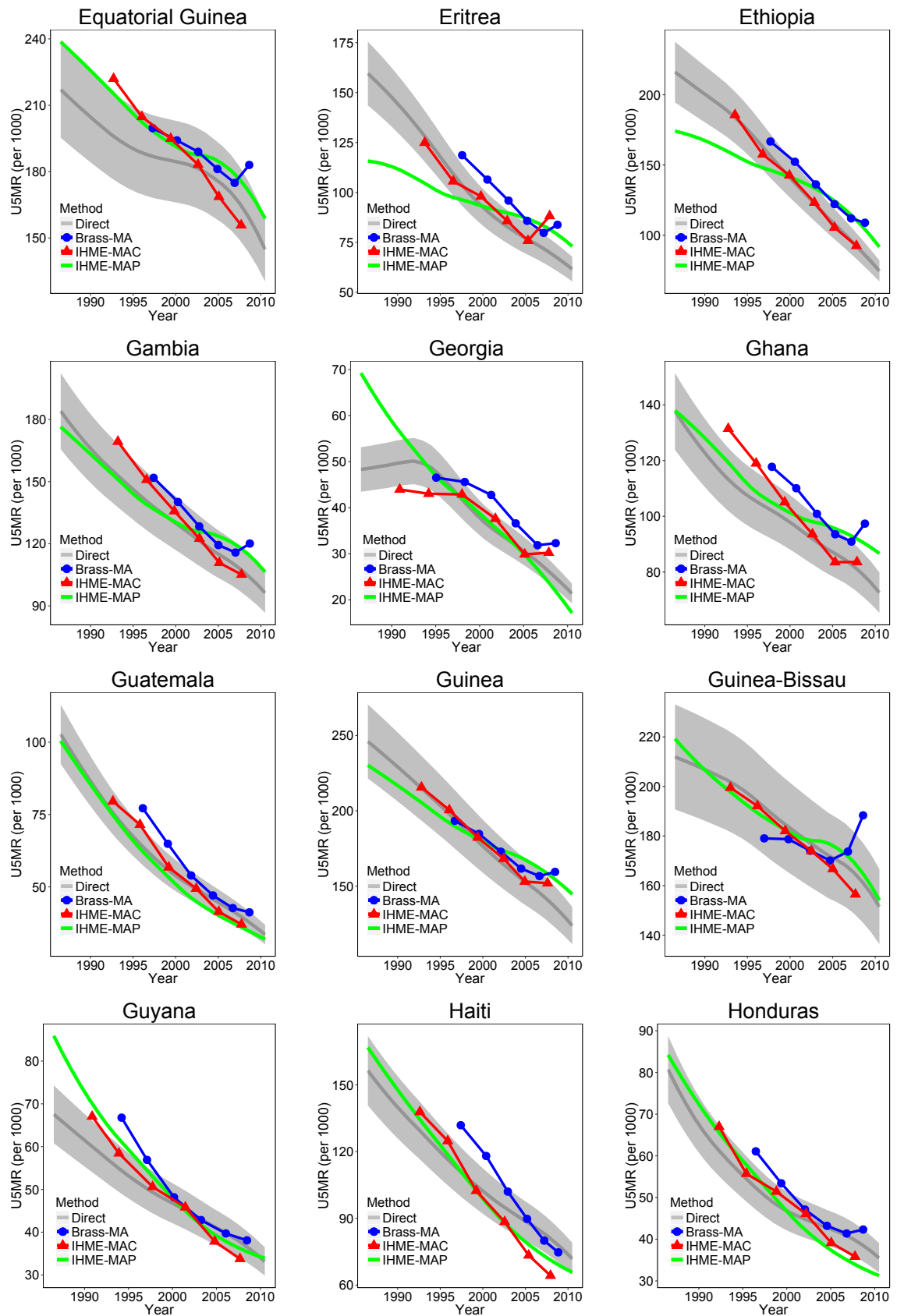
Verhulst: Child mortality estimation
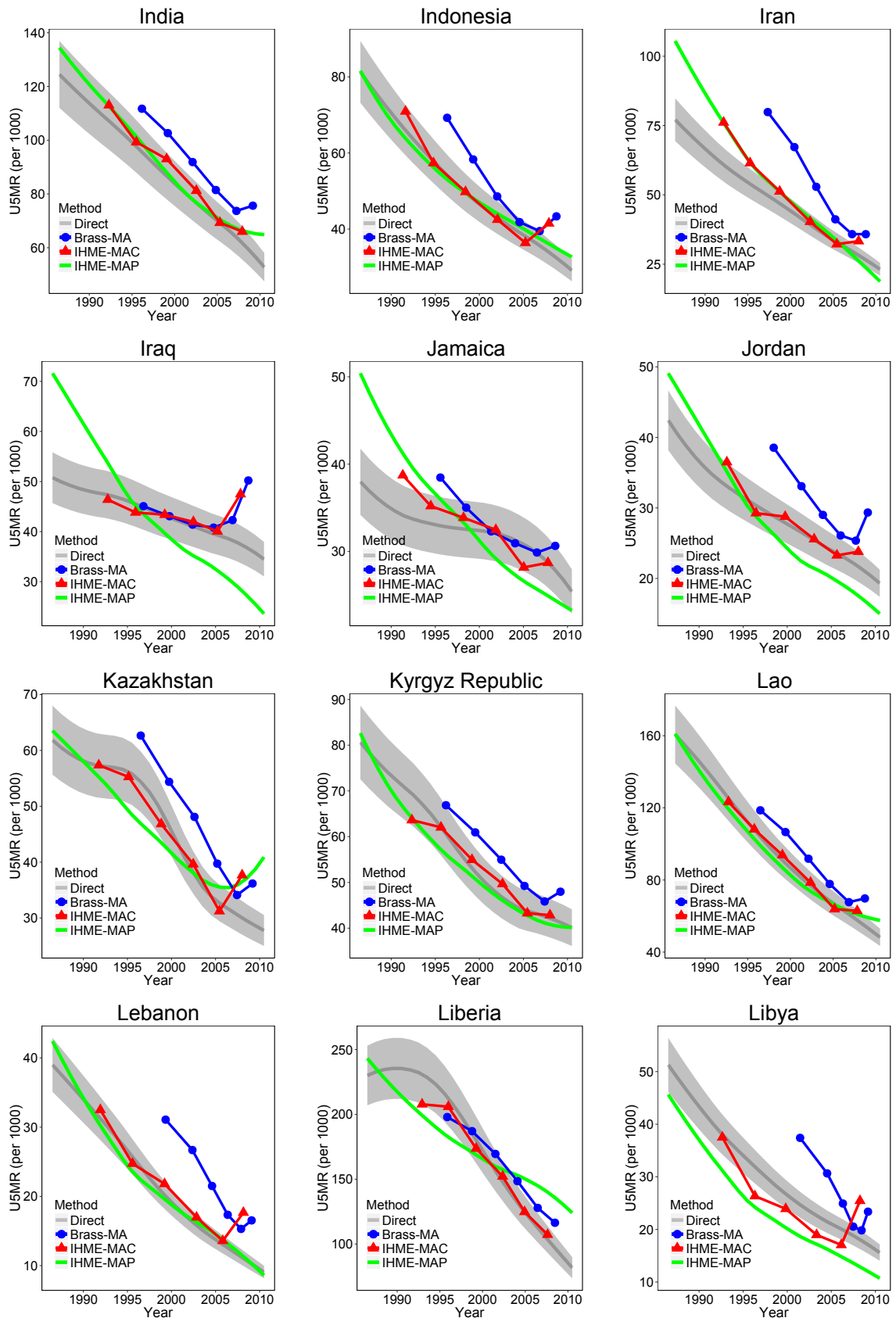

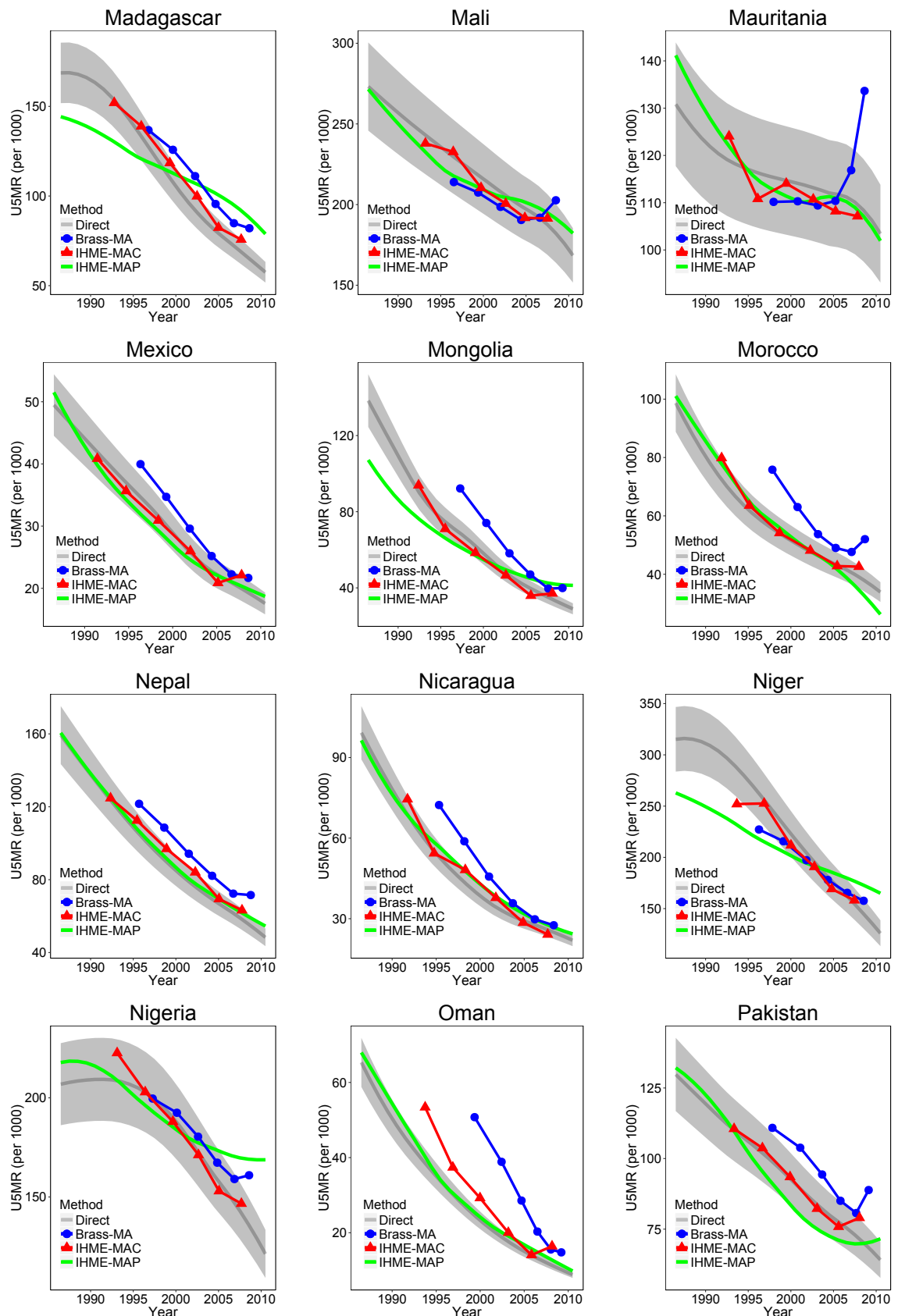

http://www.demographic-research.org 

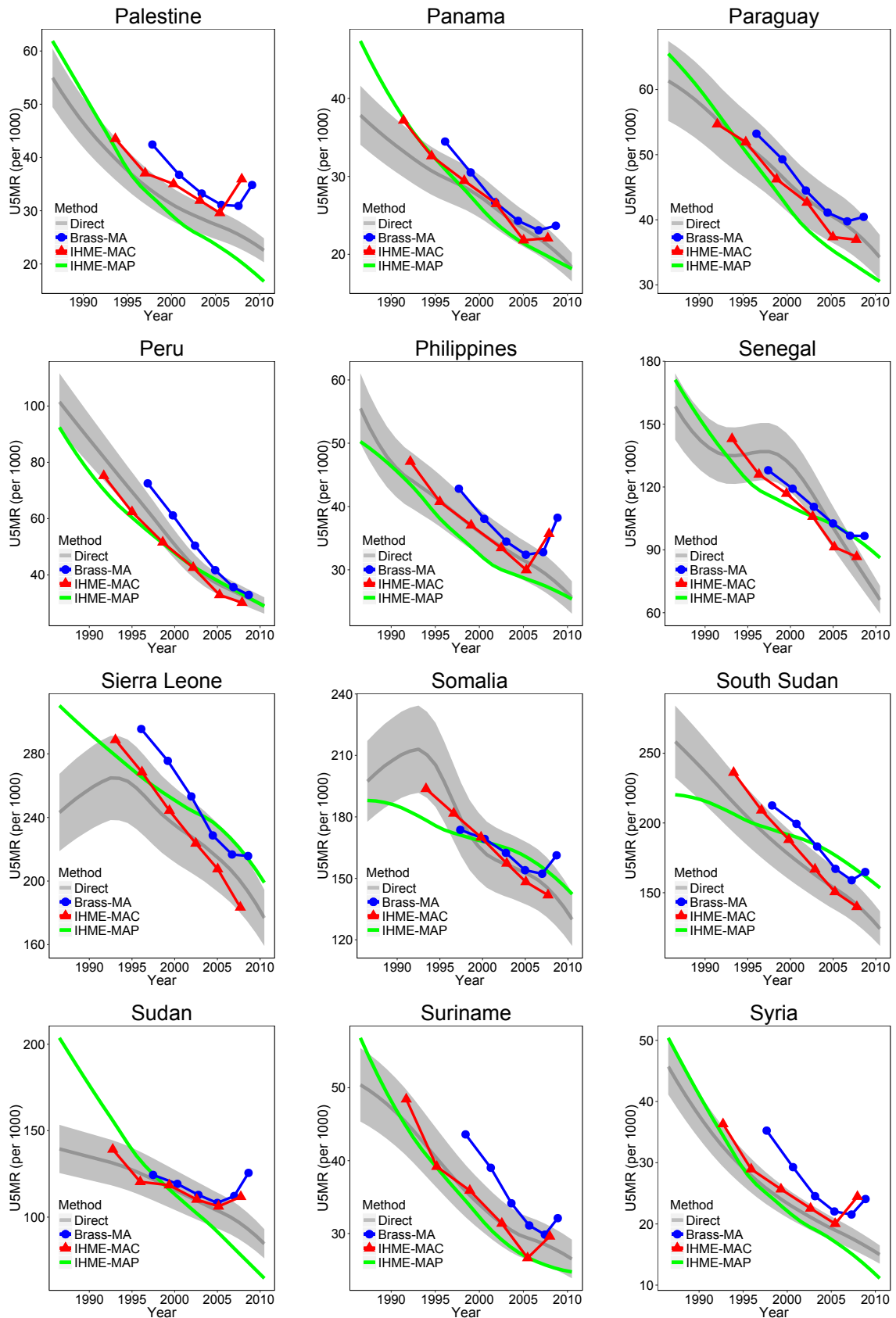

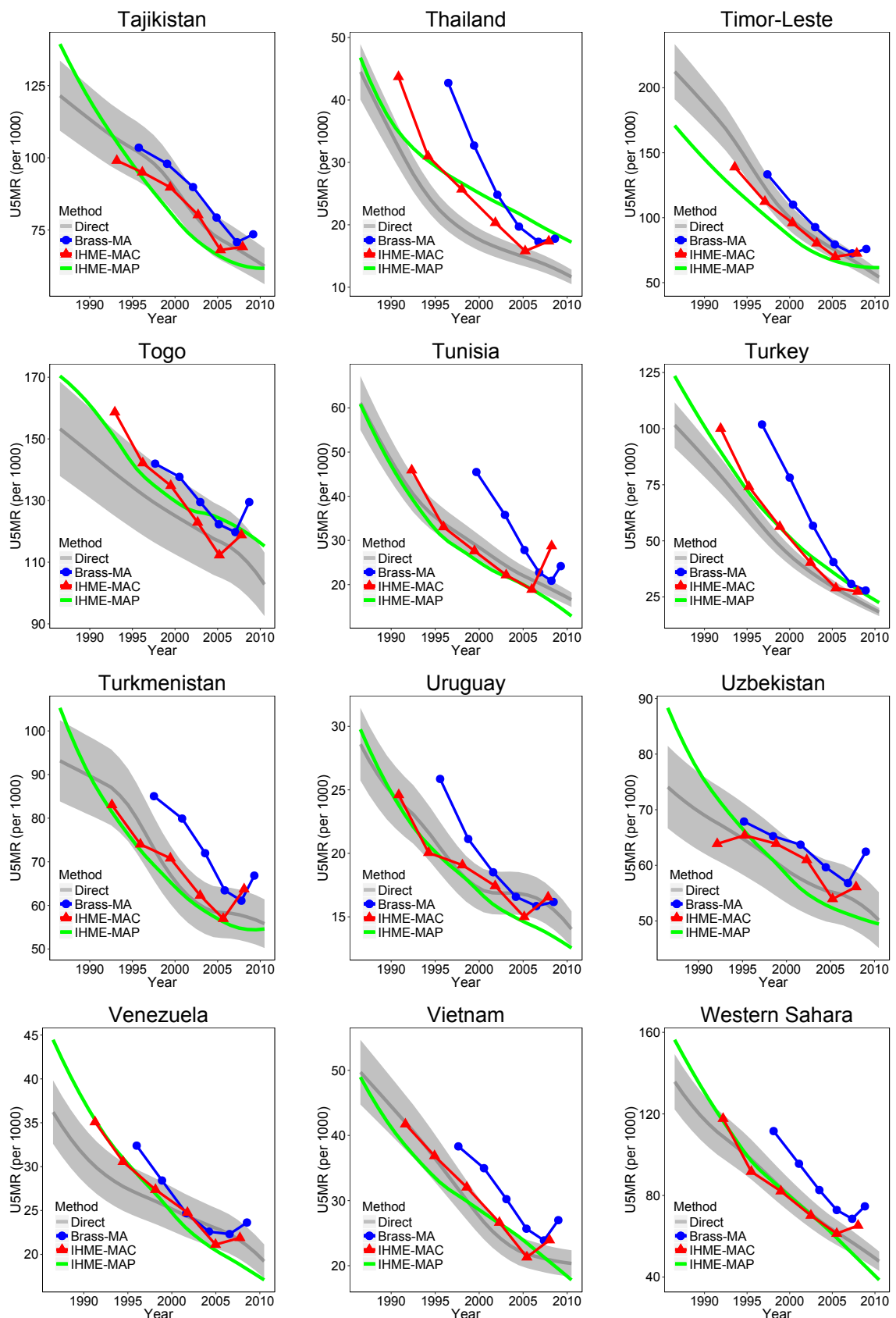
Verhulst: Child mortality estimation

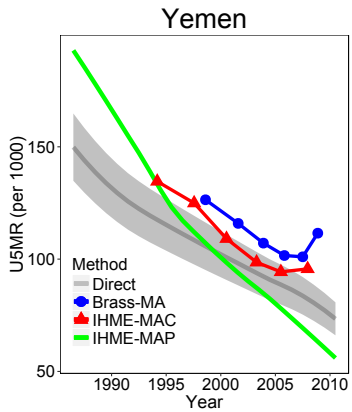


Comparison with benchmark of the under-five mortality rate estimates generated by the time since first birth summary birth history methods

Notes: The grey band delimits an upper and lower 10\% deviation interval.
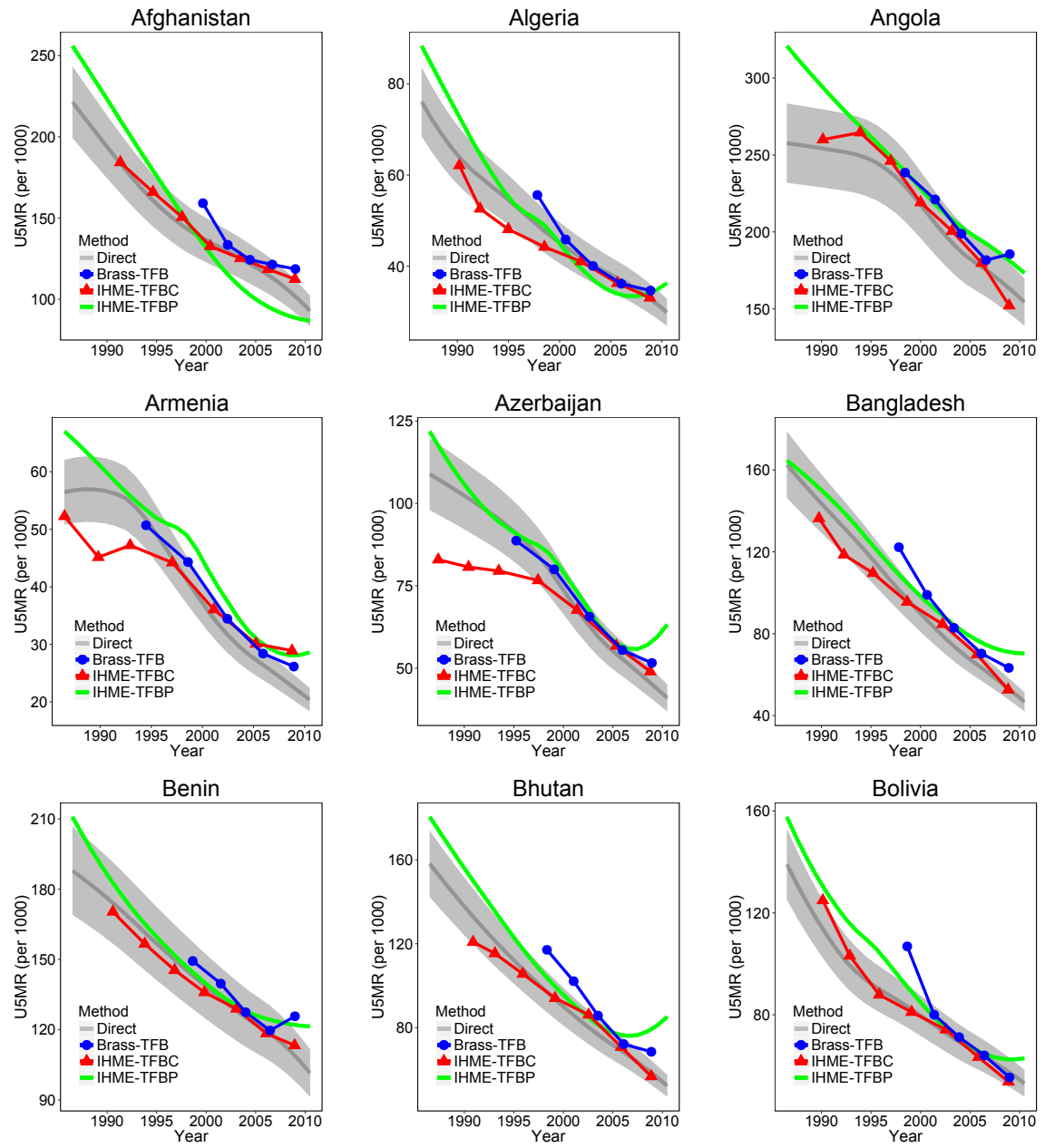
Verhulst: Child mortality estimation
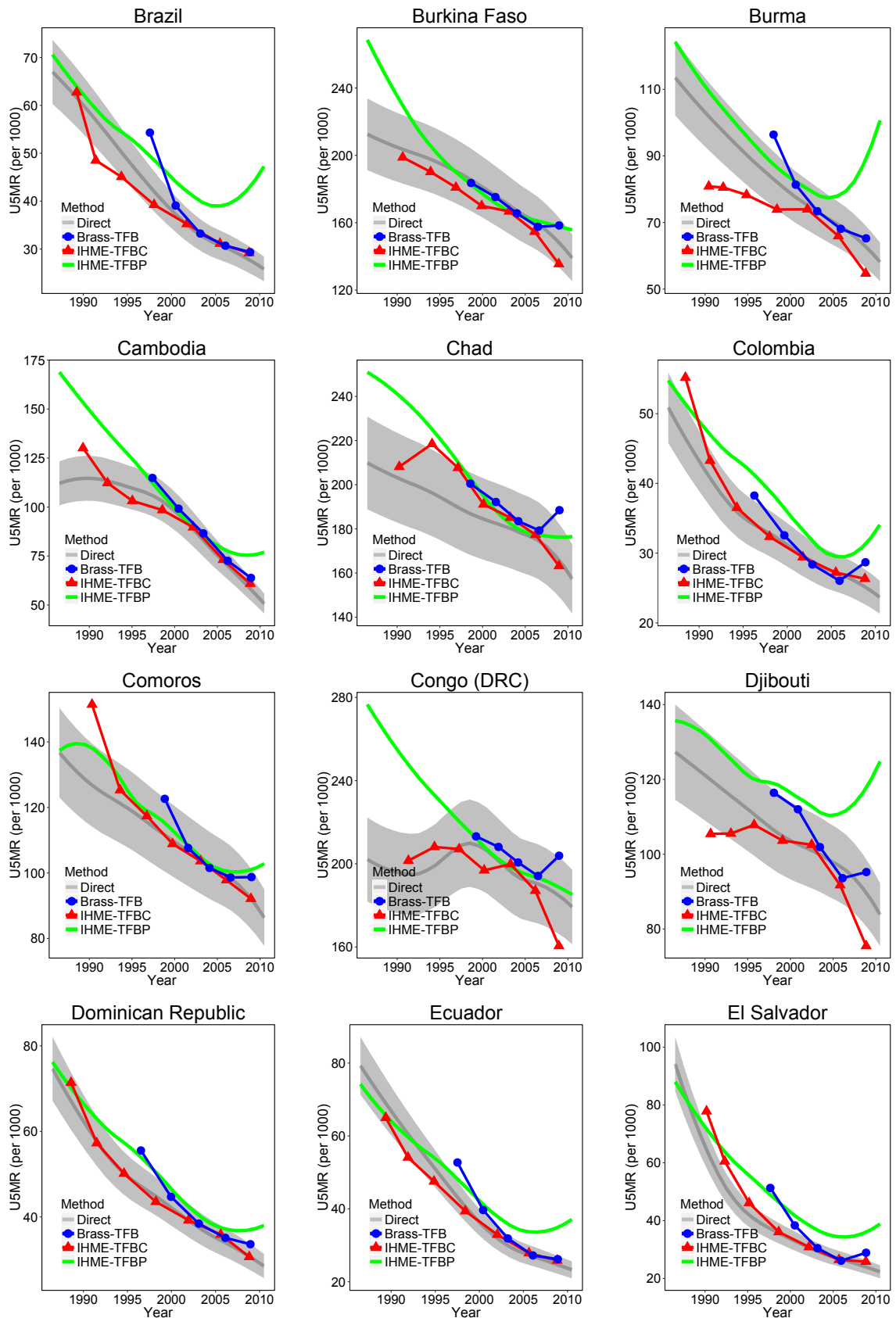

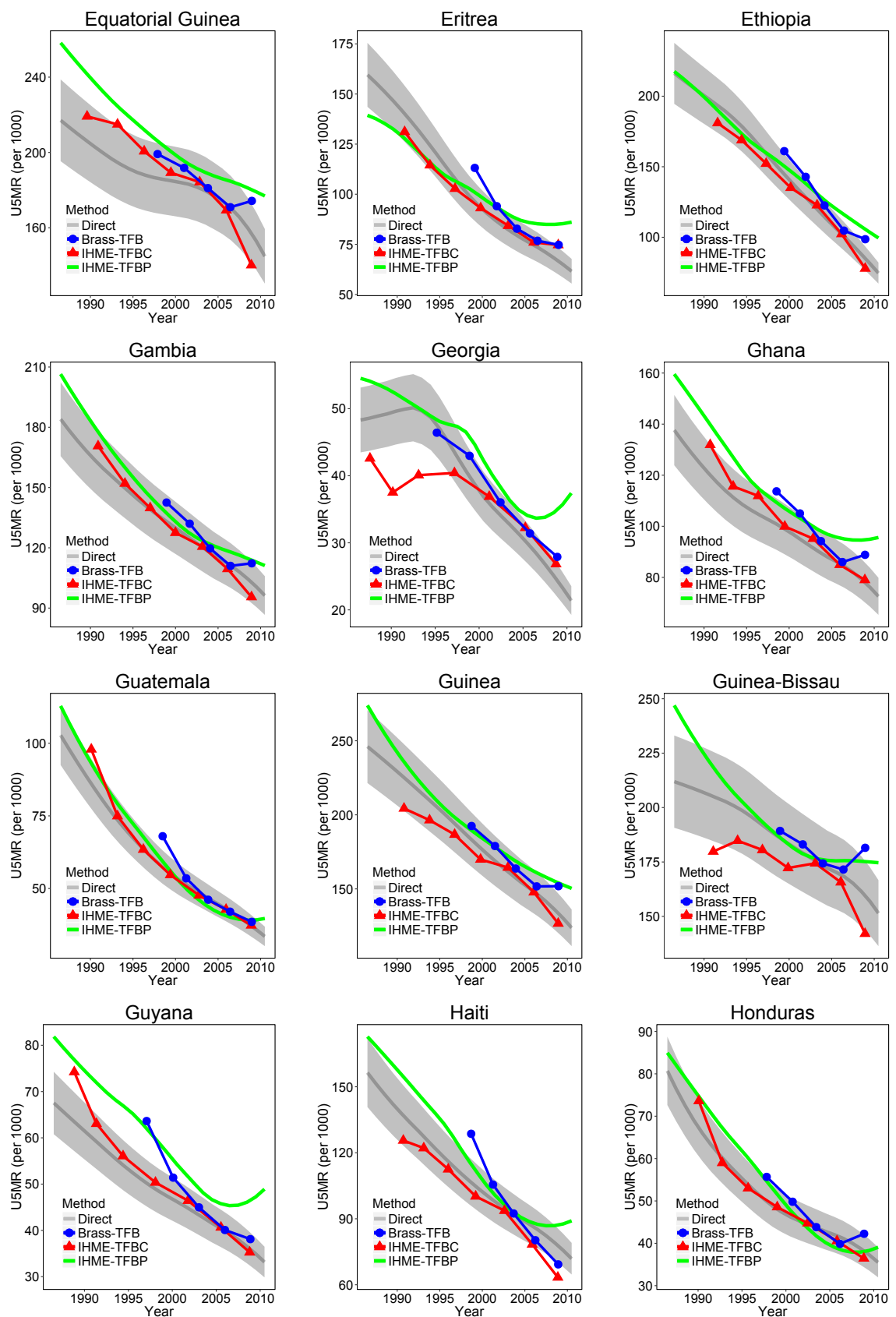
Verhulst: Child mortality estimation
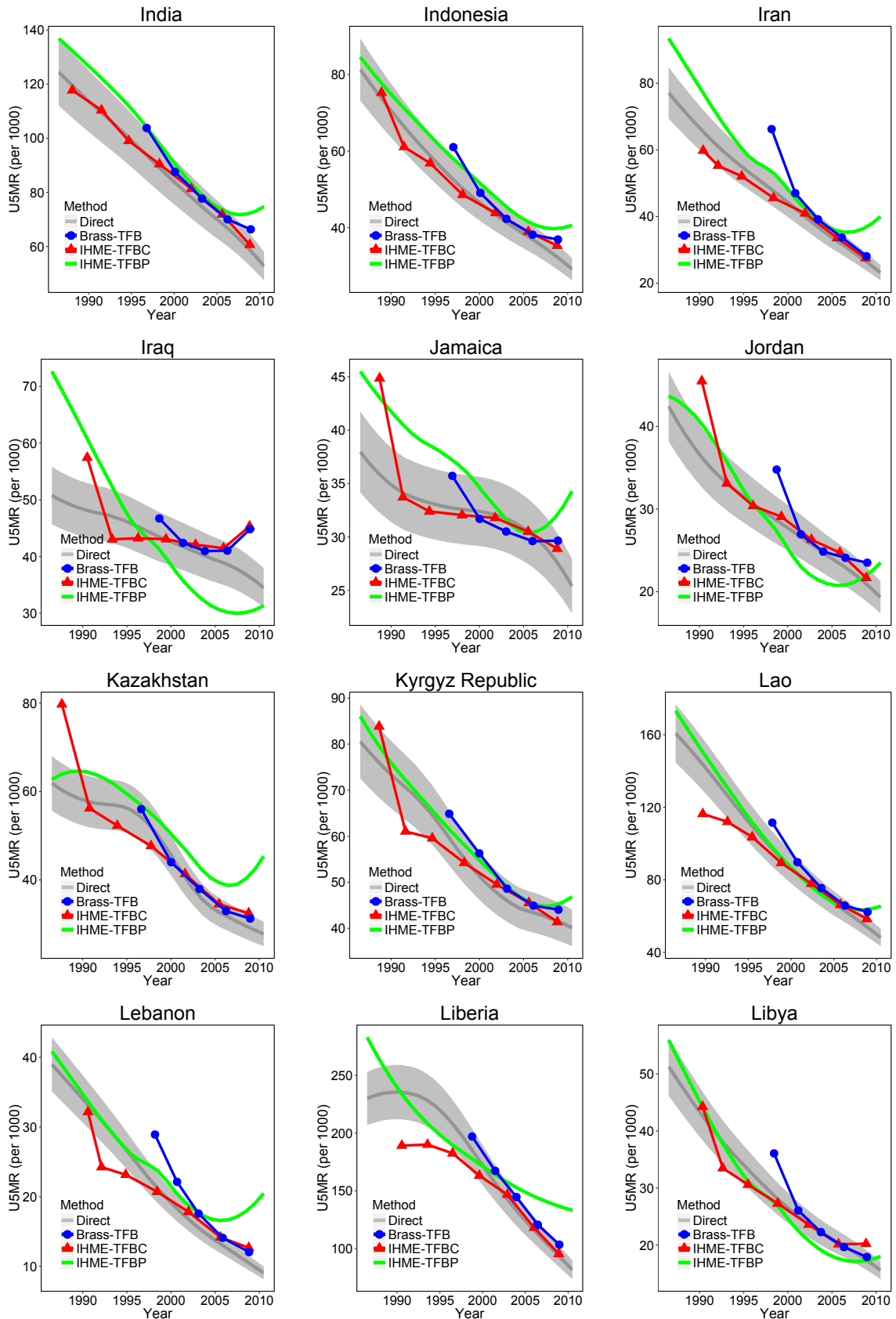

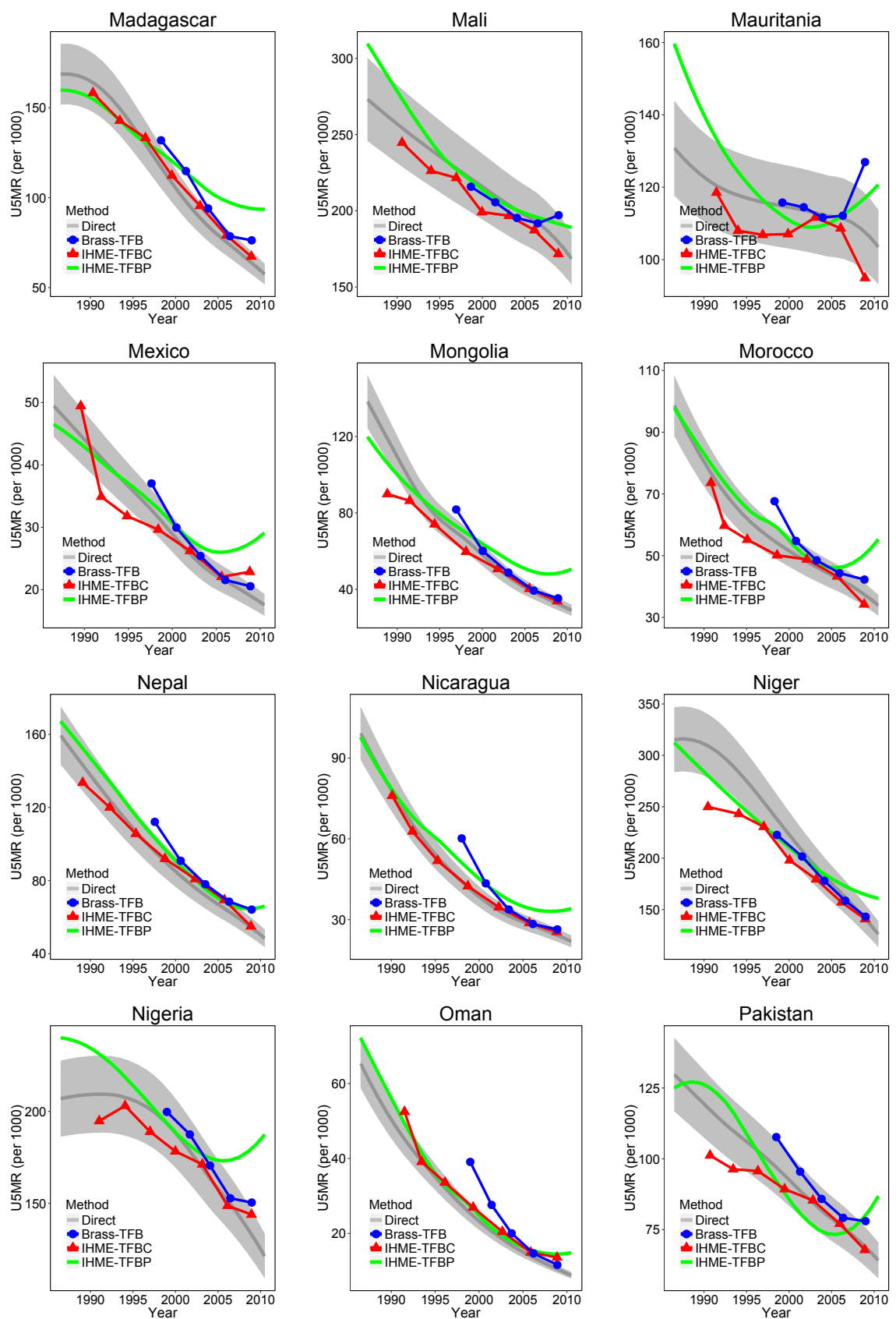

http://www.demographic-research.org 

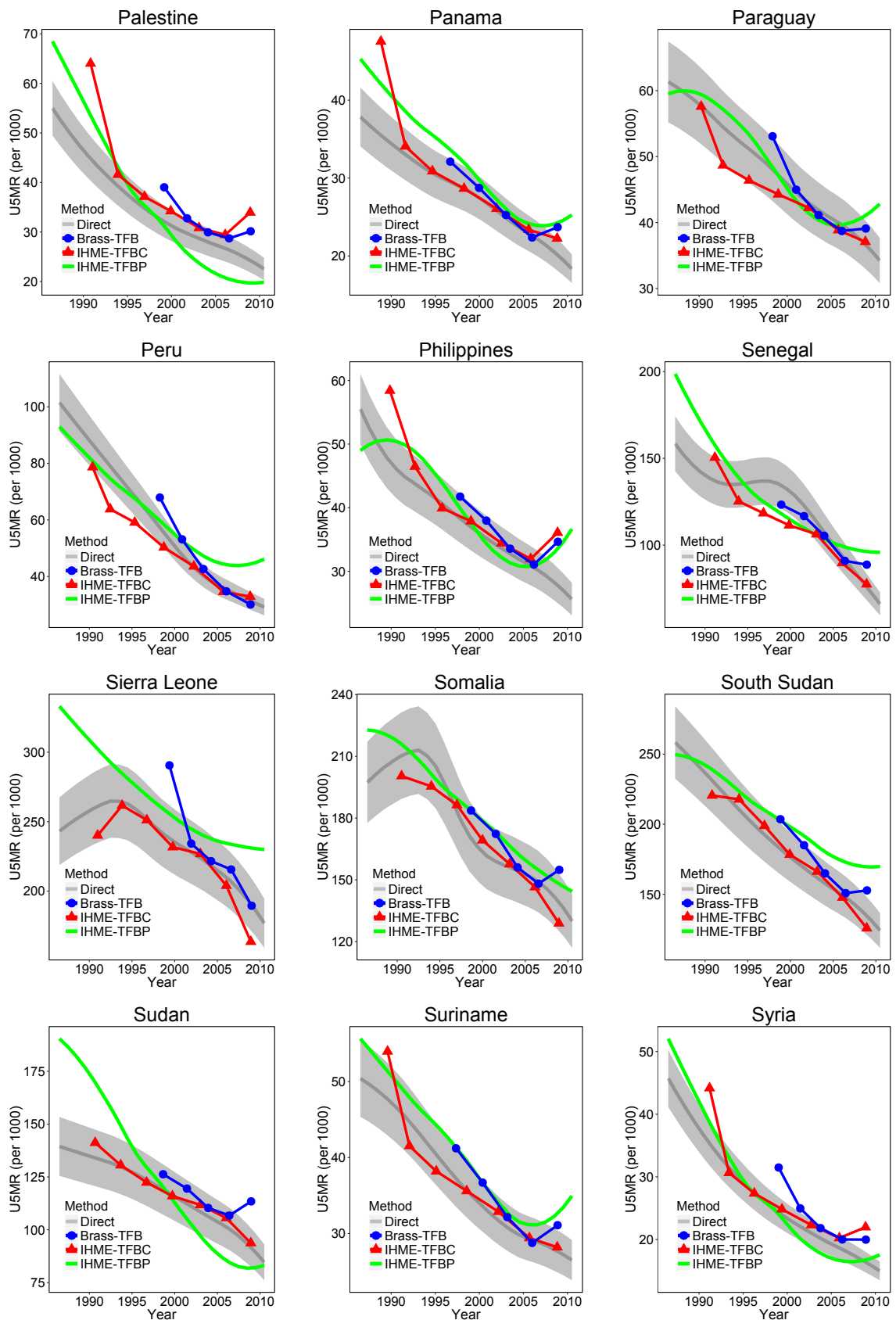

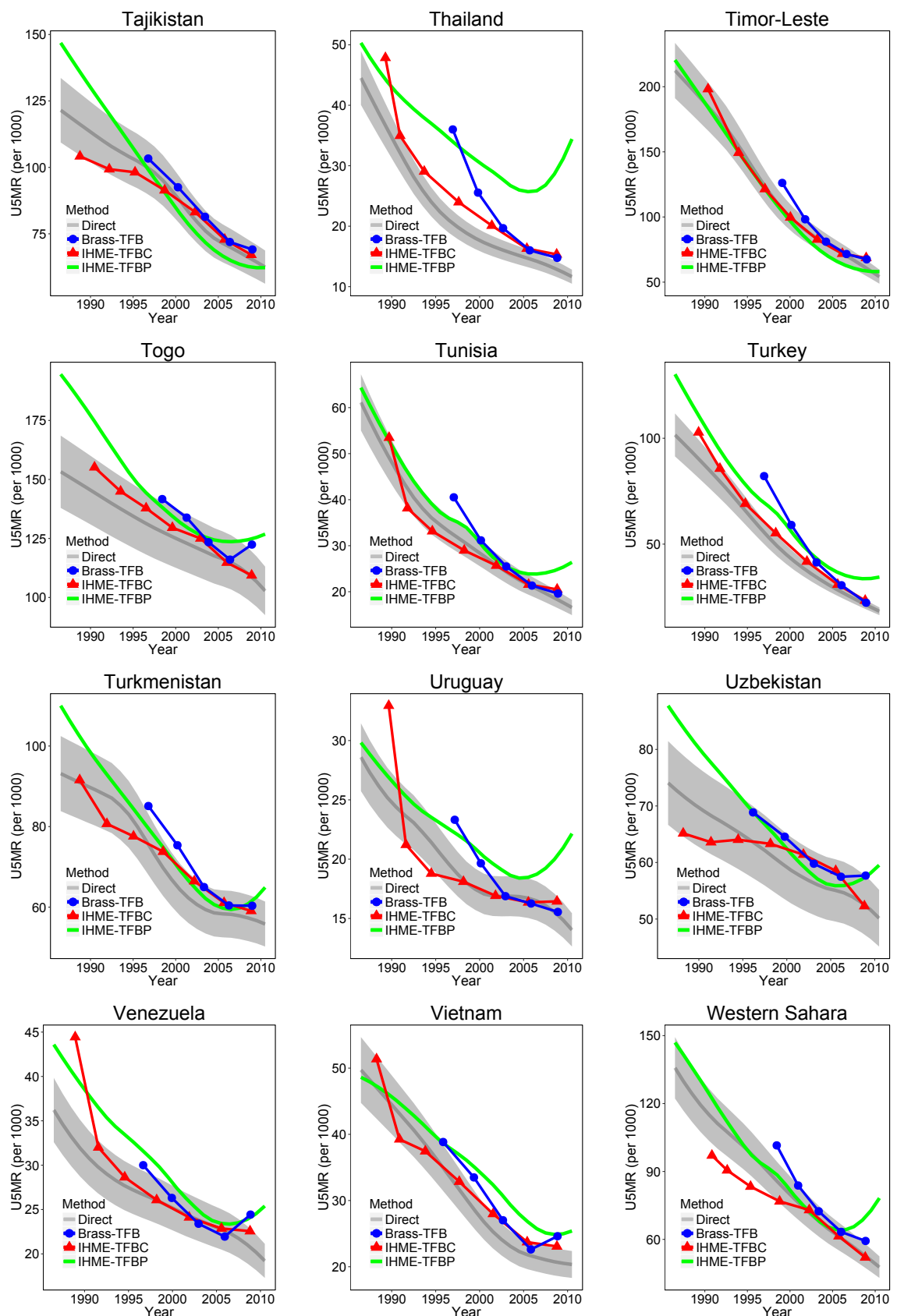
Verhulst: Child mortality estimation

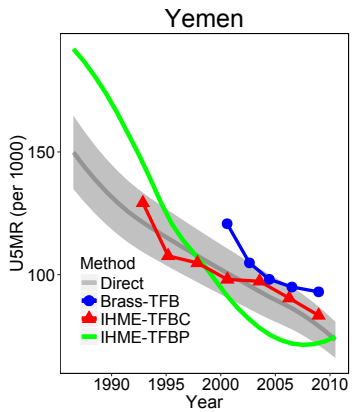

